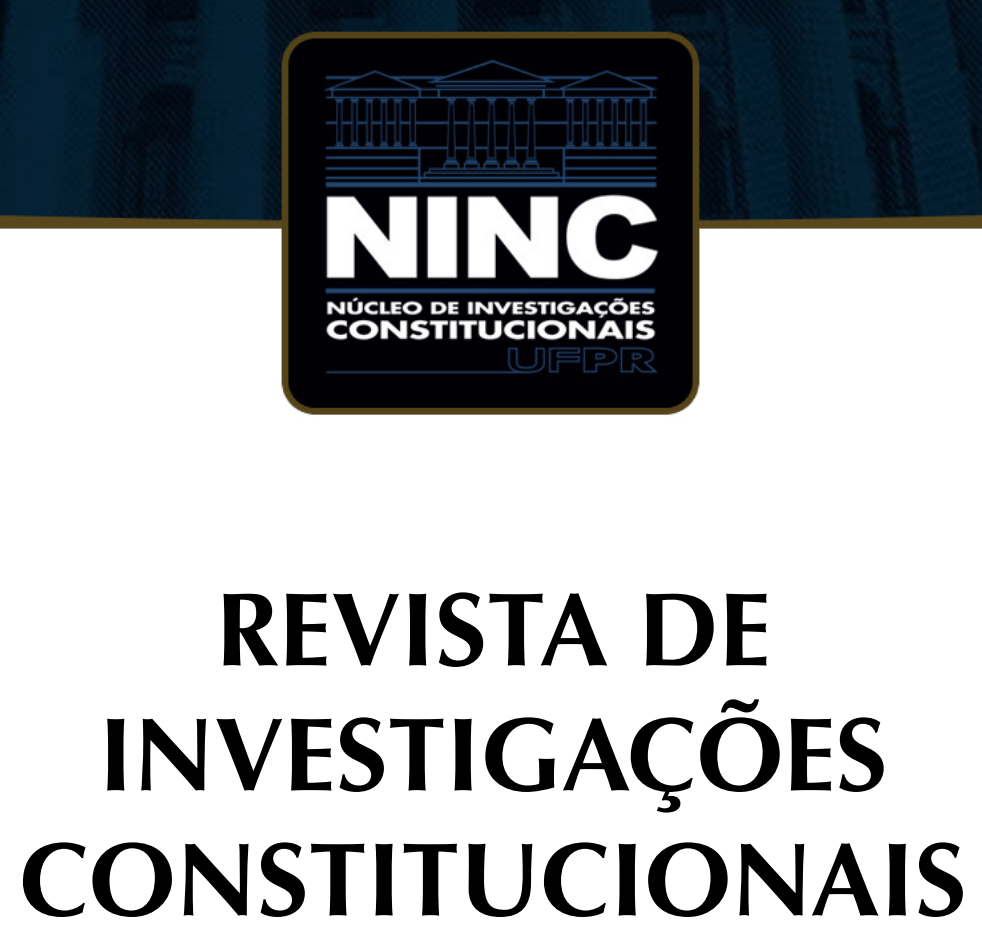

vol. 4 | n. 1 | janeiro/abril 2017 | ISSN 2359-5639 | Periodicidade quadrimestral Curitiba | Núcleo de Investigações Constitucionais da UFPR | www.ninc.com.br 


\title{
Cinco modelos de adjudicação administrativa (Justiça Administrativa)*
}

\section{Five models of Administrative Ajudication}

\author{
MICHAEL ASIMOW** \\ Stanford Law School (United States of America) \\ asimow@law.stanford.edu
}

Recebido/Received: 12.01.2017 / January 12th, 2017 Aprovado/Approved: 11.02.2017 / February 11th, 2017

\section{Resumo}

Regimes regulatórios e de distribuição de benefícios ocasionam um grande número de disputas individuais entre agências governamentais e particulares. Cada país precisa de um sistema de adjudicação administrativa para solucionar essas disputas corretamente, com justiça e eficiência. Esses sistemas geralmente compreendem três fases - decisão inicial, reconsideração administrativa e revisão judicial. Entretanto, os detalhes dos vários sistemas empregados ao redor do mundo são impressionantemente diferentes, e muitos países tendem a investir a

\section{Abstract}

Regulatory and benefit-distribution schemes give rise to large numbers of individualized disputes between government agencies and private parties. Every country needs a system of administrative adjudication to resolve such disputes accurately, fairly, and efficiently. Such systems generally provide for three phases - initial decision, administrative reconsideration, and judicial review. However, the details of the various systems employed around the world are bewilderingly diverse and different countries tend to invest most of their adjudicatory resources in only one

Como citar esse artigo/How to cite this article: ASIMOW, Michael. Cinco modelos de adjudicação administrativa (Justiça Administrativa). Revista de Investigações Constitucionais, Curitiba, vol. 4, n. 1, p. 129-165, jan./abr. 2017. DOI: 10.5380/rinc.v4i1.50154.

* Versão em inglês disponível em: http://dx.doi/org/10.5131/AJCL.2015.0001. Traduzido por Ricardo Perlingeiro (Desembargador Federal do Tribunal Regional Federal da 2a Região, e Professor Titular da Faculdade de Direito da Universidade Federal Fluminense (UFF)) e Renato Pessanha (Juiz Federal no Rio de Janeiro e Mestrando do Programa de Pós-Graduação Justiça Administrativa da UFF). Os tradutores agradecem a colaboração de Carmen Silvia Arruda, Juíza Federal no Rio de Janeiro e Doutoranda do Programa de Sociologia e Direito da UFF, e de Flávia Martins Affonso, Advogada da União no Rio de Janeiro e Doutoranda do Programa de Pós-Graduação Justiça Administrativa da UFF.

** Visiting Professor of Law na Stanford Law School (Stanford, Estados Unidos da América). Professor Emérito de Direito, UCLA School of Law. Juris Doctor - JD (University of California, Berkeley). E-mail: asimow@law.stanford.edu.

Eu agradeço a generosa ajuda de José M. Baño Fos, Yoav Dotan e Robert Rabin. Mais adiante neste artigo eu reconhecerei a ajuda de colegas que me auxiliaram a melhor compreender os sistemas de adjudicação de países específicos. Versões preliminares deste artigo foram apresentadas a pesquisadores docentes da Stanford Law School; Faculdade de Direito de Guanghua (Guanghua Law School), Universidade de Zhejiang (Hangzhou) (Zhejiang University (Hangzhou)); Faculdade de Direito da Universidade Hebrew e Faculdade de Direito de Bar llan (Israel) (Hebrew University Law School and Bar Ilan Law School (Israel)); Faculdade de Direito Torcuato di Tella e Faculdade de Direito de San Andres (Buenos Aires) (Torcuato di Tella School of Law and San Andres School of Law (Buenos Aires)); e Faculdade de Direito de Chulalongkorn (Bangkok) (Chulalongkorn Faculty of Law (Bangkok)). Ele foi também apresentado na conferência anual da Law ; Society Association em São Francisco e em uma conferência de professores de direito administrativo na Universidade de Luxemburgo (University of Luxembourg). Reconheço com gratidão as contribuições de todos aqueles que fizeram comentários nessas apresentações. 
maior parte dos recursos adjudicatórios em apenas uma dessas três fases (e os particulares que têm uma disputa com o governo tendem a confiar mais em uma das fases do que nas outras duas). Este artigo propõe uma metodologia para a classificação desses sistemas. Ele identifica quatro variáveis importantes: agências com funções combinadas ou tribunals separados; procedimento inquisitório ou adversarial; revisão judicial que pode ser aberta à introdução de novas provas ou fechada a elas; e revisão judicial feita por cortes de competência comum ou especializada. $\mathrm{O}$ artigo identifica cinco modelos mais usados ao redor do mundo, que envolvem diferentes combinações dessas variáveis. Os Estados Unidos, por exemplo, utilizam agências com funções combinadas, procedimento adversarial e revisão judicial fechada procedida por cortes de competência comum. Por outro lado, o Reino Unido utiliza um tribunal independente para reconsiderar decisões iniciais das agências. A França utiliza o sistema de revisão judicial aberta efetuada por uma corte especializada. Cada um desses modelos pode oferecer decisões corretas e eficientes, preservando a justiça. Finalmente, o artigo discute transplantes de um sistema de adjudicação administrativa para outro. Existem vários exemplos de transplantes bem sucedidos. $\mathrm{O}$ artigo sugere que os Estados Unidos deveriam considerar a adoção de um tribunal para a seguridade social (à semelhança dos tribunals do Reino Unido e da Austrália) para substituir o atual sistema de adjudicação nos litígios envolvendo a seguridade social.

Palavras-chave: justiça administrativa; jurisdição administrativa; revisão judicial; processo administrativo; Direito comparado. of the three phases (and private parties who have dispute with government tend to have more confidence in one of the phases than in the other two). This article proposes a methodology for classifying such systems. It identifies four key variables: combined function agencies or separate tribunals, adversarial or inquisitorial procedure, judicial review that is open to introduction of new evidence or closed to new evidence, and judicial review by generalized or specialized courts. The article identifies five models in common use around the world that involve different combinations of these variables. The United States, for example, uses combined function agencies, adversarial procedure, and closed judicial review in generalist courts. On the other hand, the United Kingdom employs an independent tribunal to reconsider initial agency decisions. And France employs open judicial review in a specialized court. Each of these models can deliver accurate and efficient decisions while preserving fairness. Finally, the article discusses transplants from one administrative adjudicatory system to another. There are numerous examples of successful transplants. The article suggests that the United States should consider adopting a Social Security tribunal (similar to the tribunals in the United Kingdom and Australia) to replace the present system of adjudication of Social Security disputes.

Keywords: administrative justice; administrative jurisdiction; judicial review, administrative proceedings; Comparative Law.

\section{SUMÁRIO}

1. Introdução; 2. Três Fases, Quatro Variáveis e Cinco Modelos; 3. Descrição Detalhada dos Modelos; 3.1. Modelo 1: Funções combinadas / Audiência adversarial / Revisão judicial fechada em cortes de competência comum - Os Estados Unidos; 3.2. Modelo 2: Decisão inicial e reconsideração inquisitórias - União Europeia; 3.3. Modelo 3: Tribunals - Reino Unido, Austrália; 3.4. Modelo 4: Revisão Judicial Aberta - China, Argentina e Japão; 3.5. Modelo 5: Revisão judicial em cortes especializadas - França e Alemanha; 4. Avaliando e transplantando sistemas de adjudicação; 5. Conclusão; 6. Referências.

\section{INTRODUÇÃO}

Os sistemas de regulação governamental e de distribuição de benefícios geram disputas entre o governo e os particulares. Essas disputas podem envolver a negativa de um pedido de concessão de benefícios governamentais, uma decisão sancionatória, como a imposição de uma multa civil ou a revogação de uma licença, ou uma ação regulatória que obrigue um particular a fazer ou deixar de fazer algo. $\mathrm{O}$ direito 
administrativo deve prescrever um sistema de adjudicação que resolva essas disputas de um modo correto, justo e eficiente. 1

Pela expressão "adjudicação administrativa" refiro-me a todo sistema de solução de conflitos individuais entre particulares e agências administrativas governamentais (government administrative agencies), ${ }^{2}$ começando com a investigação administrativa e a decisão preliminar da agência (agency's preliminary or "front-line" decision3), prosseguindo com o processo pelo qual o particular desafia essa decisão preliminar e concluindo com a revisão judicial. 4

Uma lista dos tipos de adjudicação administrativa poderia ser quase infinita. Apenas para mencionar alguns: estaria realmente incapacitado o requerente de um benefício? Estaria em perigo um não cidadão caso viesse a ser deportado para o seu país de origem? Teria um professor assediado sexualmente um estudante? Teria o titular de uma licença infringido a legislação ambiental? Teria um corretor de ações cometido fraude contra os consumidores? Se uma agência nega um benefício ou impõe uma sanção ou outra limitação administrativa, o que fazer? Se alguma infração é identificada, quais são as consequências? Deveria um professor ser demitido? Deveria uma licença ser revogada? Poderia a agência exigir uma multa? A maioria desses casos exige uma solução de disputas versando sobre fatos adjudicáveis, 5 a aplicação das leis aos fatos, ou o exercício da discricionariedade administrativa, 6 ao invés de questões de direito ou de política pública.

Os sistemas estabelecidos pelos países para resolução desses conflitos variam muito e são de difícil comparação. Este artigo destaca cinco modelos utilizados por diversos países que podem facilitar o exercício dessa comparação.

$A$ adjudicação administrativa é um tema importante e que merece uma maior atenção acadêmica do que efetivamente recebe. De fato, a adjudicação não é a área

\footnotetext{
1 Na maioria dos países funcionários da Administração solucionam disputas entre particulares (e também as disputas entre particulares e o governo). As cortes são sensíveis ao risco que a atribuição da tarefa de decidir os conflitos envolvendo particulares e agências pode representar ameaça aos poderes judiciais. Este artigo não discute a forma como os diferentes países enfrentam essa tensão. Do mesmo modo, o artigo não discute ações administrativas de caráter geral, como a elaboração de normas. Ele também não trata das disputas que são direcionadas às cortes, e não às agências administrativas, para a decisão inicial, como as demandas propostas contra o governo envolvendo responsabilidade civil ou contratual.

2 Uso o termo "agência (agency)" na acepção em que ele é usado no direito dos EUA, significando uma unidade governamental (diferente de uma corte ou de um órgão legislativo) com poder delegado para afetar direitos e obrigações através da elaboração de normas, adjudicação ou funções similares. O termo inclui unidades governamentais de várias espécies usadas pelo mundo, incluindo ministérios e departamentos.

3 Ver nota 8.

4 Em muitos países as decisões administrativas de adjudicação proferidas pelas agências governamentais são referidas como "atos administrativos", "decisões" ou "atos unilaterais".

5 Uso o termo "adjudicative facts" para me referir àqueles que têm relação específica com as partes envolvidas na controvérsia, em oposição a "legislative facts" que são aqueles de aplicação geral.

6 Uso o termo "discretion" para me referir à prerrogativa de uma agência de fazer escolhas entre alternativas na aplicação de uma norma, como, por exemplo, na decisão sobre a intensidade de uma sanção.
} 
mais glamourosa do direito administrativo contemporâneo. Os trabalhos de ponta na atualidade se concentram na elaboração de políticas públicas, análise de custo-benefício, responsabilização e dever de prestação de contas (accountability), parceria público-privada, redes de trabalho, separação de poderes e outros temas importantes da atualidade.7 Adjudicação administrativa corresponde ao direito administrativo aplicado ao nível do varejo, e não por atacado. Agências raramente se utilizam dela para estabelecer políticas ou criar precedentes (embora, obviamente, por vezes o façam).

Adjudicação traz à lembrança a imagem de demorados procedimentos, com autos volumosos (na esfera regulatória) ou corredores cheios de requerentes insatisfeitos esperando por uma audiência apressada perante um funcionário impaciente (na área de benefícios governamentais e imigração). O resultado da maioria das disputas administrativas não é muito importante para o governo, mas é de importância vital para os particulares que desafiam o governo. Em muitos países o volume de adjudicações administrativas excede largamente a quantidade de casos submetidos ao Judiciário. Por essas razões, a adjudicação administrativa está a merecer maior atenção acadêmica. $O$ direito comparado auxilia os acadêmicos, e aqueles que elaboram as políticas, a melhor compreenderem seus próprios sistemas de adjudicação administrativa e os abastecem com ideias extraídas de outros sistemas que são capazes de aperfeiçoá-los.

A Parte I deste artigo descreve sua metodologia. A Parte ll apresenta uma descrição detalhada dos cinco modelos da forma como são empregados em vários países e a Parte III explora a possibilidade de transplante para outros sistemas.

\section{TRÊS FASES, QUATRO VARIÁVEIS E CINCO MODELOS}

A maioria dos sistemas de adjudicação administrativa tem três fases: ${ }^{8}$

1. Decisão inicial. Por decisão inicial refiro-me ao primeiro procedimento da agência que permite ao particular uma oportunidade formal para oferecer suas alegações e contestar o primeiro ato administrativo ("front-line" determination) dos agentes da Administração. ${ }^{9}$ A decisão inicial torna-se

\footnotetext{
7 Ver BIGNAMI, F. From Expert Administration to Accountability Network: A New Paradigm for Comparative Administrative Law. American Journal of Comparative Law, Washington, v. 59, n. 4, p. 859-908, 2011.

8 De fato, a adjudicação tem normalmente quatro fases ao invés de três. As três mencionadas no texto são geralmente precedidas de uma investigação preliminar e uma "front-line" decision dos funcionários da agência. $\mathrm{Na}$ fase de investigação preliminar o pessoal da agência investiga se um requerente teria o direito de receber um benefício ou se um particular poderia ser alvo de uma sanção ou de alguma outra imposição regulatória e produzem uma "front-line decision" segundo as conclusões dessa investigação. Essa sequência de investigação e "front-line decision" poderia ser denominada "fase zero". Este artigo terá pouco a dizer sobre a fase zero, dado que é difícil de investigar, na maioria das vezes sem uma previsão legal e específica para o regime administrativo particular ao qual ela se aplica. Quando o artigo faz referência às "três fases" da adjudicação administrativa está, por conseguinte, excluindo a "fase zero".

9 Ver nota 8 sobre a discussão da front-line decision.
} 
compulsória, salvo se vier a ser impugnada em nível hierárquico mais elevado.

2. Reconsideração administrativa. A maioria dos sistemas administrativos inclui uma disposição pela qual a decisão inicial pode ser reconsiderada administrativamente, seja por um agente de nível hierárquico superior, dentro da mesma agência, seja por outra agência.

3. Revisão judicial. A maioria dos sistemas administrativos inclui uma oportunidade conferida aos particulares para pleitearem a revisão da decisão inicial, ou daquela proferida em reconsideração, perante uma corte. ${ }^{10}$

Existem quatro variáveis importantes. Cada uma requer uma escolha. As duas primeiras variáveis dizem respeito às fases de decisão inicial e de reconsideração. As duas últimas estão relacionadas à revisão judicial.

Variável 1:Trata-se de um corpo de adjudicadores de uma agência com funções combinadas ou de um tribunal separado? Uma agência com funções combinadas acumula atribuições de investigação, persecução, decisão inicial e reconsideração. Um tribunal separado atua na fase de reconsideração, mas não se encarrega das etapas de investigação ou de persecução.

Variável 2: É o processo inquisitório ou adversarial? Processos adversariais se parecem com o modelo de julgamento de causas criminais adotado nos Estados Unidos e no Reino Unido - significando um processo conduzido por advogado perante um juiz relativamente passivo e independente. O julgamento é nitidamente separado da fase de investigação do caso. Procedimentos inquisitórios se parecem com os processos criminais europeus ou latino-americanos, o que significa que um investigador prepara um dossiê e chega a uma conclusão sobre culpa ou inocência. Nos sistemas inquisitórios, a fase da decisão inicial é conduzida mais pelos investigadores do que pelos advogados. A decisão inicial oferece ao particular uma oportunidade de apresentar alegações orais ou escritas no intuito de influenciar o convencimento dos investigadores. Do mesmo modo, um procedimento de reconsideração de natureza inquisitória é pouco formal e conduzido pelos agentes incumbidos da análise do pedido de reconsideração. Obviamente, nenhum sistema pode ser qualificado de puramente "adversarial" ou puramente "inquisitório". Todavia, processos podem ser agrupados segundo esse eixo e tenderão a se aproximar do polo "adversarial" ou do polo "inquisitório".

Variável 3: O sistema de revisão judicial é aberto ou fechado? Em um sistema aberto, tanto as partes podem apresentar novas provas em uma corte (em complemento

10 Para os objetivos deste artigo, o termo "judicial review" inclui recurso. Muitos países distinguem os dois, tratando o recurso como um remédio originário da norma legal escrita e "judicial review" como um direito não positivado. 
àquelas apresentadas nas fases anteriores) como a corte pode determinar-lhes a produção de novas provas. Qualquer das partes pode oferecer novos argumentos que não tenham sido apresentados nos estágios precedentes e o governo pode apresentar novas justificativas para seus atos que não tenham sido anteriormente declinadas. Em outras palavras, em um sistema aberto, os elementos de convicção a serem analisados não se estabilizam até o estágio da revisão judicial. Em um sistema fechado, as partes não podem introduzir novas provas, novas razões ou novos argumentos. O processo já está completo, seja no estágio da decisão inicial ou no de reconsideração.

Variável 4: Tem a corte de revisão judicial uma competência comum ou se trata de uma corte especializada administrativa?

Este artigo identifica cinco modelos de adjudicação administrativa. Os modelos descrevem diferentes maneiras que países usam para combinar essas quatro variáveis ao estruturar as fases de decisão inicial, reconsideração e revisão judicial. Cada um dos cinco modelos envolve uma alteração de uma única variável em relação aos modelos anteriormente descritos. Os métodos de adjudicação administrativa dos países ou entidades supranacionais cujos sistemas são tratados neste artigo (Estados Unidos, União Europeia, Reino Unido, Austrália, China, Argentina, Japão, França e Alemanha) podem ser descritos tomando por referência um desses cinco modelos.

Cada país tende a confiar primordialmente em uma dessas três fases (que é, decisão inicial, reconsideração ou revisão judicial) para atingir um resultado justo e correto. Preocupações com eficiência impõem aos países essa escolha. Os países não podem suportar o investimento de recursos similares em duas, muito menos em três dessas fases. A fase que cada país escolhe como destinatária da maior parte dos recursos será provavelmente aquela em que os particulares identificarão as melhores chances de vencerem o caso.

Nesse ponto, introduzo algumas ressalvas metodológicas. Primeiramente, a abordagem deste artigo para definir os modelos de adjudicação administrativa adotados por diversos países simplifica demasiadamente os detalhes dos mecanismos de decisão por eles adotados. A simplificação é uma falha inevitável na construção de modelos nas ciências sociais. É necessário resumir sistemas altamente complexos a fim de compará-los e contrastá-los com exemplos extraídos de outros países. Espero que minha descrição desses vários sistemas de adjudicação não distorça sua essência. Em segundo lugar, por razões políticas e históricas, os sistemas de adjudicação administrativa de cada um dos países citados não podem ser identificados com as características de um único modelo. Como será examinado abaixo, os Estados Unidos, por exemplo, têm um modelo predominante, mas cada um dos quatro outros modelos pode ser encontrado em algum lugar no direito administrativo norte americano. ${ }^{11}$ Acredito que o

11 Ver o texto das notas $26-27$. 
modelo que selecionei para descrever o sistema praticado em cada país em particular é o caminho paradigmático que esse país escolheu para organizar sua adjudicação administrativa. É o modelo que os elaboradores das políticas governamentais desse país irão escolher, a menos que haja fortes razões para a adoção de outro. Eu agora sintetizo os cinco modelos e na Parte Il os discutirei em maiores detalhes.

\begin{tabular}{|c|c|c|}
\hline Modelo & Descrição & Países \\
\hline 1 & $\begin{array}{ll}\text { - } & \text { Funções combinadas } \\
\text { - } & \text { Adversarial } \\
\text { - } & \text { Revisão fechada } \\
\text { - } & \text { Cortes de competência comum }\end{array}$ & Estados Unidos \\
\hline 2 & $\begin{array}{ll}\text { - } & \text { Funções combinadas } \\
\text { - } & \text { Inquisitório } \\
\text { - } & \text { Revisão fechada } \\
\text { - } & \text { Cortes de competência comum }\end{array}$ & União Europeia \\
\hline 3 & $\begin{array}{ll}\text { - } & \text { Tribunal } \\
\text { - } & \text { Adversarial } \\
\text { - } & \text { Revisão fechada } \\
\text { - } & \text { Cortes de competência comum }\end{array}$ & $\begin{array}{l}\text { Reino Unido } \\
\text { Austrália }\end{array}$ \\
\hline 4 & $\begin{array}{ll}\text { - } & \text { Funções combinadas } \\
\text { - } & \text { Inquisitório } \\
\text { - } & \text { Revisão aberta } \\
\text { - } & \text { Cortes de competência comum } \\
\end{array}$ & $\begin{array}{l}\text { China } \\
\text { Argentina } \\
\text { Japão }\end{array}$ \\
\hline 5 & $\begin{array}{ll}\text { - } & \text { Funções combinadas } \\
\text { - } & \text { Inquisitório } \\
\text { - } & \text { Revisão aberta } \\
\text { - } & \text { Cortes especializadas }\end{array}$ & $\begin{array}{l}\text { França } \\
\text { Alemanha }\end{array}$ \\
\hline
\end{tabular}

Modelo 1 - Audiência (hearing) adversarial / Funções combinadas / Revisão judicial limitada

De acordo com o primeiro modelo, a agência que profere a decisão inicial e a de reconsideração é uma agência com funções combinadas. Ela promove uma audiência adversarial formal, típica de um julgamento, presidida por um oficial denominado Hearing Officer - HO.12 O HO trabalha na agência em questão, mas não toma parte da

$12 \mathrm{Na}$ praxe dos EUA o HO é frequentemente citado como um juiz administrativo ou como um juiz de direito administrativo (ALJ), ou ainda por algum outro título (como, por exemplo, Juiz de Imigração). Trato dessa questão de nomenclatura abaixo, no texto das notas 20-21. Na maioria dos países, todavia, um $\mathrm{HO}$ administrativo não poderia ser citado como um "juiz", haja vista que apenas os julgadores integrantes do sistema judicial podem receber esse título. 
investigação ou da persecução do caso que ele decide (isso refere-se a "separação de funções"). A fase de reconsideração se dá em um nível mais elevado da mesma agência que proferiu a decisão inicial. Cortes de competência comum procedem à revisão judicial quanto à legalidade e razoabilidade da decisão da agência. A revisão judicial é fechada (significando que não há possibilidade de apresentação de novas provas, novos argumentos ou novas razões) e a corte não substitui a decisão da agência no que diz respeito a questões de direito, de fato ou discricionariedade. Esse modelo é normalmente empregado nas agências federais e estaduais dos Estados Unidos.

Modelo 2 - Audiência (hearing) inquisitória / Funções combinadas / Revisão judicial limitada

O Modelo 2 é similar ao Modelo 1, exceto que a decisão inicial e a fase de reconsideração são inquisitórias ao invés de assegurarem o modelo adversarial. Não há separação de funções, o que significa dizer que a mesma pessoa ou pessoas exercem as funções de investigação, de persecução e de adjudicação. Procedimentos em nível de decisão inicial são considerados parte integrante da investigação. O responsável pela decisão é ativo, ao invés de passivo, e auxilia as partes sem representação. A revisão judicial é fechada. Ela é feita perante cortes de competência comum. Esse modelo é empregado em casos decididos ao nível da União Europeia (UE), mas não nos casos decididos pelos Estados membros da UE.

Modelo 3 - Sistema de tribunals 13

O Modelo 3 é parecido com o Modelo 1, exceto que a decisão em reconsideração é proferida por um tribunal administrativo que é separado do órgão de investigação e persecução. Esse modelo de tribunal é aplicado na Austrália e no Reino Unido, e em numerosos países cujos sistemas legais derivam do Reino Unido.

Modelo 4 - Revisão judicial aberta

As fases de decisão inicial e de reconsideração do Modelo 4 são semelhantes àquelas do Modelo 2. Entretanto, a revisão judicial é aberta, significando que a corte pode apreciar novas provas, razões e argumentos, e que a corte tem a prerrogativa de substituir a decisão da Administração pela sua, no que diz respeito a questões de fato e que envolvam o exercício do poder discricionário, assim como naquelas que envolvam legalidade. Esse modelo é empregado na China, Argentina e Japão.

Modelo 5 - Cortes especializadas

No modelo 5, as fases de decisão inicial e de reconsideração são parecidas com o Modelo 2, porém a corte que conduz a revisão judicial é destacada do sistema judiciário de competência comum e decide apenas questões de direito administrativo. Esse

\footnotetext{
13 Em alguns países a palavra "tribunal" é usada como referência a cortes. Uso esse termo para fazer referência a uma estrutura decisória administrativa que é independente da agência que produziu a decisão inicial, mas que não é uma corte.
} 
modelo é empregado na França, Alemanha, e muitos outros países na Europa, Ásia e América Latina.

Obviamente, as quatro variáveis poderiam ser manipuladas a fim de produzir muito mais do que cinco modelos. Contudo, esses cinco descrevem os sistemas de adjudicação administrativa que encontrei, incluindo-se aqueles adotados por muitos países não mencionados neste artigo.

Talvez um exemplo concreto venha esclarecer como os cinco modelos podem funcionar na solução de um simples conflito envolvendo a Administração. Imagine que o Ministério dos Transportes (MT) no país $C$ licencie a exploração de um serviço de balsas. A autorização contém uma série de disposições relativas à segurança e proteção do meio ambiente. Uma das disposições proíbe a eliminação de resíduos produzidos nas balsas jogando-os na água. Cap opera um serviço de balsas sob essa licença. MT recebe uma denúncia feita por Ed (antigo empregado de Cap), investiga o caso e acusa Cap de eliminação indevida de resíduos na água. Essa é a decisão preliminar (front-line decision) do MT.14

Durante o processo de decisão inicial, Ed presta declaração (oralmente ou por escrito) afirmando que viu Cap eliminando resíduos dentro da água. Cap presta declaração afirmando que demitiu Ed por incompetência no ano anterior e que Ed tem um ressentimento contra ele. Cap nega que tenha atirado resíduos na água e testemunha afirmando que essa eliminação é sempre feita da maneira apropriada. Vários outros empregados de Cap testemunham que jamais viram a eliminação indevida de resíduos e que a política da companhia proíbe essa prática. O oficial do MT responsável pela decisão inicial decide que Cap eliminou os resíduos em descumprimento aos termos da licença que dispunha e recomenda que ela seja revogada (ao invés de impor uma multa pecuniária contra ele). MT ou um tribunal aprecia o pedido de reconsideração dessa decisão e confirma a penalidade. Cap busca a revisão judicial. Na revisão não há controvérsias de direito ou de procedimento. A única controvérsia é saber quem está falando a verdade - Cap ou Ed - e, se a persecução de eliminação indevida de resíduos for mantida, se a licença de Cap deve ser revogada.

Modelo 1: MT é uma agência com funções combinadas, significando que é o responsável pela persecução, investigação, adjudicação e reconsideração. Ele promove uma formal, típica de julgamento, audiência adversarial presidida por um oficial denominado Hearing Officer - HO que não tenha participado da investigação e da persecução do caso de Cap. A decisão do HO revoga a licença de Cap. A autoridade superior no MT aprecia o pedido de reconsideração da decisão do HO, e a mantém. A decisão do MT é submetida a revisão perante uma corte de competência comum em um processo fechado. A corte deve confirmar a decisão do MT (tanto no que diz respeito às

14 Ver nota 8. 
conclusões de fato como em relação ao exercício da discricionariedade na imposição da penalidade administrativa) se ela for razoável.

Modelo 2: Modelo 2 é igual ao Modelo 1, excetuando que as fases de decisão inicial e reconsideração são inquisitórias ao invés de adversariais. A audiência é tratada como parte da investigação levada a efeito pela agência. Ela é conduzida por investigadores e acusadores (prosecutors) do MT ao invés de um HO.

Modelo 3: Modelo 3 é igual ao Modelo 1, exceto que a reconsideração é promovida por um tribunal que é independente do MT.

Modelo 4: Modelo 4 é igual ao Modelo 2, excetuando que a revisão é aberta ao invés de fechada. Isso significa que as cortes têm a prerrogativa de receber novas provas e novos argumentos de ambas as partes e o MT pode introduzir novas razões para justificar a adoção de sua decisão discricionária. A corte tem o poder de substituir o julgamento do MT tanto no que diz respeito a questões de fato, quanto de discricionariedade.

Modelo 5: Modelo 5 é igual ao Modelo 4, excetuando que a revisão é efetuada por uma corte especializada em questões administrativas, ao invés de ser procedida por uma corte de competência comum.

\section{DESCRIÇÃO DETALHADA DOS MODELOS}

Esta parte do texto fornece uma descrição mais detalhada dos cinco modelos da forma como eles são aplicados em vários países.

\subsection{Modelo 1: Funções combinadas / Audiência (hearing) adversarial / Revisão judicial fechada em cortes de competência comum - Os Estados Unidos}

O modelo de funções combinadas adotado nos Estados Unidos é proveniente do esforço para regular as ferrovias durante as eras populista e progressiva (The Populist and Progressive Eras) no fim dos anos 1800 e início dos anos 1900.15 Várias falhas de mercado tornaram imperativa alguma forma de regulação. Todos os lados do conflito - incluindo ferrovias e transportadores - pressionaram por uma regulação federal, que resultou na criação, em 1887, da Comissão de Comércio Interestadual (Interstate Commerce Commission - ICC).

Embora a versão original da ICC fosse em grande medida enfraquecida (e mesmo os poderes reduzidos que ela possuía foram logo retirados pelas cortes), até 1920

15 Ver RABIN, R. Federal Regulation in Historical Perspective. Standford Law Review, Stanford, v. 38, n. 5, p. 1189-1326, 1986. p. 1318. O ICC foi extinto em 1995 e algumas de suas funções foram assumidas por outras agências. 
a ICC havia surgido como o protótipo de uma agência de regulação econômica com funções combinadas. Ela tinha ampla autoridade para regular as ferrovias, incluindo o poder de expedir regulamentos, fixar e controlar as tarifas nas ferrovias e rejeitar fusões. A ICC decidia casos envolvendo ferrovias acusadas de terem violado normas da regulação, assim como disputas entre transportadores e ferrovias a respeito da razoabilidade das tarifas.

A ICC era uma clássica agência de funções combinadas, significando que ela expedia normas, investigava, procedia à persecução e conduzia as fases de decisão inicial e de reconsideração. O Congresso dos Estados Unidos seguiu esse modelo quando criou, em 1914, a Comissão Federal do Comércio (Federal Trade Commission - FTC). A FTC era uma agência de monitoramento com poder para investigar, acusar e decidir sobre reclamações contra práticas anticompetitivas. Legislaturas adaptaram o modelo de funções combinadas para inúmeras agências regulatórias e de distribuição de benefícios, em nível federal e estadual, ao longo do século vinte e mesmo no século vinte e um.

Entre 1906 e 1920, a ICC começou a utilizar Hearing Officers - HO para conduzir a fase de decisão inicial nas questões envolvendo as tarifas das ferrovias. Esses processos referentes à decisão inicial eram adversariais e assemelhavam-se a um julgamento civil com a participação dominante de advogados. O HOs redigiam detalhadas decisões iniciais que se tornavam definitivas e vinculantes, a menos que fossem reconsideradas pelos diretores da agência. O Congresso reproduziu essa abordagem ao utilizar um Hearing Officer $(\mathrm{HO})$ de funções combinadas nas legislações subsequentes, como, por exemplo, na Lei da Comissão Federal do Comércio (Federal Trade Commission Act). 16

A Lei de Processo Administrativo (Administrative Procedure Act - APA) de 194617 preservou as agências de funções combinadas, embora os oponentes do New Deal tenham tentado separar as funções de decisão inicial e de reconsideração das funções de investigação e de persecução. As disposições relativas à adjudicação administrativa constantes do APA contemplam audiências adversariais conduzidas por HOs que trabalham para a agência que faz a persecução, porém, dentro de uma estrutura em separado dos investigadores e acusadores (prosecutors). 18 Em 1978, os HOs sujeitos ao estatuto da APA receberam um novo e apreciado título - Administrative Law Judges (ALJs).

\footnotetext{
16 Lei da Comissão Federal do Comércio dos Estados Unidos (15 U.S.Code §§ 41-58 de 2012). Ver GIFFORD, D. J. Federal Administrative Law Judges: The Relevance of Past Choices to Future Directions. Administrative Law Review, Washington, v. 49, n. 1, p. 4-5, 1997.

17 Lei de Processo Administrativo dos Estados Unidos [Administrative Procedure Act - APA / Public Law no 79-404, 60 Stat. 237].

18 Ver 5 U.S.Code. $§ \S 554,556-67$ de 2012.
} 
A mais importante inovação introduzida pelo APA nas normas relativas a adjudicação foi o conjunto de garantias objetivando assegurar a independência do HO.19 No entanto, é importante observar que a maioria dos $\mathrm{HO}$ empregados pelas agências federais não são ALJs, uma vez que as audiências que eles conduzem não são reguladas pelo APA. 20 Por essa razão, este artigo faz referência a "hearing officers - $H O$ " ao invés de utilizar-se da denominação mais usual "administrative law judges ( $A L J)$ ".

A distribuição de competência para a tomada de decisão nas agências com funções combinadas é relativamente uniforme, independentemente de esse processo estar submetido ao APA ou não. Como demonstrado no hipotético caso da exploração do sistema de balsas, ${ }^{21}$ um HO profere a decisão inicial após a condução de um processo adversarial quase judicial. O HO não está pessoalmente envolvido na investigação ou persecução do caso (em outras palavras, existe uma separação interna de funções). $\mathrm{O} \mathrm{HO}$ redige uma decisão inicial que contém descrição detalhada das conclusões e dos fundamentos. Essa decisão se torna definitiva a menos que um dos lados requeira reconsideração.

O diretor da agência exerce a função de reconsideração, que também é adversarial. Acusadores (prosecutors) e investigadores não têm contato pessoal com o diretor da agência sem a presença da outra parte. O diretor da agência tem o poder de proferir nova decisão em substituição à decisão inicial.22 A função de reconsideração é exercida com base nas provas produzidas durante a audiência inicial; as partes apresentam seus argumentos oralmente e por escrito, mas normalmente não se admite a introdução de novas provas. A cláusula do devido processo na Constituição dos Estados Unidos, ${ }^{23}$ assim como as disposições contidas nos APAs estaduais e federais garantem um processo

19 Ver 5 U.S.Code. $\S \S 3105,5372,7521$ de 2012. ALJs são contratados por uma agência separada, o Office of Personnel Management (OPM) através de um rigoroso processo de testes e entrevistas, não pela agência para a qual eles julgarão os processos. Uma vez contratados, os ALJs gozam de vitaliciedade sem qualquer período probatório, e não podem ser exonerados, exceto por uma justa causa. Processos envolvendo exoneração de ALJs por uma justa causa são julgados por ALJs que trabalham em uma agência separada, o Merit Systems Protection Board. ALJs não possuem outra atribuição além do julgamento de processos administrativos e, na medida do possível, devem ser designados para os processos com alternância. Eles não estão submetidos a avaliações de performance. O APA contém um rígido sistema de separação de funções, de maneira que os investigadores e acusadores (prosecutors) vinculados à agência (também chamados "adversaries") não podem empreender comunicações off-the-record com os julgadores (ou seja, tanto os ALJs quanto os diretores das agências) sobre as questões envolvendo um processo em tramitação.

20 Por exemplo, processos tão importantes quanto os de benefícios destinados aos veteranos de guerra e os de imigração não são submetidos ao APA. Ver ASIMOW, M. The Spreading Umbrella: Extending the APA's Adjudication Provisions to All Evidentiary Hearings Required by Statute. Administrative Law Review, Washington, v. 56, p. 1003-1008, 2004.

21 Ver supra o texto da nota 8.

22 Entretanto, os poderes dos órgãos de reconsideração são limitados na capacidade de modificar as conclusões de fato estabelecidas na decisão inicial, na medida em que essas conclusões foram fundamentadas na apreciação da credibilidade das testemunhas. ESTADOS UNIDOS. Corte Suprema. Caso Universal Camera Corp. v. NLRB, 340 U.S. 474. Washington, 26 de fevereiro de 1951.

23 Art. V (para agências federais), art. XIV (para agências estaduais e locais) da Constituição dos Estados Unidos. 
justo tanto na decisão inicial como na reconsideração, e a imparcialidade do $\mathrm{HO}$ e do diretor da agência.

O APA não alterou significativamente a revisão judicial. Cortes federais ou estaduais de competência comum procedem a revisão judicial fechada. Em outras palavras, nenhuma das partes pode apresentar provas ou argumentos que não tenham sido apresentados na esfera administrativa e a agência não pode invocar novos fundamentos para sua decisão. As cortes devem confirmar as conclusões sobre a matéria fática e os atos praticados no exercício do poder discricionário, se ambos tiverem observado parâmetros de razoabilidade. No sistema federal, a corte deve também confirmar uma interpretação legal razoável procedida pela agência a respeito de uma lei ou regulamento ambíguo,24 porém as cortes estaduais normalmente possuem plenos poderes para decidir acerca de questões de direito.

Como acima mencionado, um país tende a confiar mais em apenas uma das três fases da adjudicação para alcançar um resultado correto e justo. No Modelo 1, de países como os Estados Unidos, essa fase é a decisão inicial que frequentemente envolve uma audiência de julgamento adversarial perante um $\mathrm{HO}$ relativamente independente. Muito menos recursos são investidos na reconsideração e na revisão judicial, que são destinadas ao controle da decisão inicial destituída de razoabilidade e juridicamente equivocada. Advogados investem a maior parte dos seus esforços na fase da decisão inicial, considerando que é improvável, durante as fases de reconsideração e de revisão judicial, que ela venha a ser modificada com base em erro na interpretação dos fatos ou no exercício da discricionariedade administrativa.

Como também acima destacado, os verdadeiros detalhes dos sistemas de adjudicação administrativa de cada país não podem ser condensados dentro de um único modelo. Existem exceções para toda generalização. $\mathrm{O}$ desenho dos sistemas de adjudicação administrativa existentes no espectro do direito administrativo é moldado por circunstâncias históricas e lutas políticas, e não por reprodução mecânica de modelos já existentes. Nos Estados Unidos, por exemplo, é possível encontrar sistemas de adjudicação administrativa nos níveis federal, estadual e local que são melhor descritos pelos Modelos 2 a 5 do que no Modelo 1. Acredito, entretanto, que o Modelo 1 é o paradigma nos Estados Unidos, isto é, o mais característico método de organização da adjudicação administrativa; ele apresenta o padrão a ser seguido a menos que haja boas razões para a utilização de outro. Os parágrafos seguintes, porém, ilustram algumas exceções a essa generalização. O mesmo se aplica aos outros países mencionados neste artigo.

Primeiramente, o procedimento de decisão inicial em muitas das agências que tratam da concessão de benefícios (particularmente os benefícios da seguridade social

24 ESTADOS UNIDOS. Suprema Corte. Caso Chevron USA, Inc. v. Natural Resources Defense Council, 467 U.S. 837. Washington, 25 de junho de 1984; ESTADOS UNIDOS. Suprema Corte. Caso Auer v. Robbins, 519 U.S. 452. Washington, 19 de fevereiro de 1997. 
e os concedidos aos veteranos de guerra) é inquisitório em certos aspectos. Geralmente o governo não está representado por advogado, então o HO é responsável por representar o interesse de ambas as partes, decidindo em seguida o caso. ${ }^{25}$ Nesse particular, esses importantes sistemas de adjudicação se parecem mais com o Modelo 2 do que com o Modelo 1.26 Os sistemas de benefícios da seguridade social e dos veteranos de guerra adjudicam mais de um milhão de casos por ano, provavelmente mais do que todos as demais agências federais combinadas.

Em segundo lugar, existem numerosos tribunals no sistema dos EUA (o que significa dizer que a decisão inicial é passível de reconsideração por uma agência independente com poderes de adjudicação). Por exemplo, em vários estados, a reconsideração da decisão inicial das agências que tratam da concessão de benefícios (como a compensação por acidentes do trabalho ou seguro desemprego) é realizada por um tribunal separado. Existem muitos tribunals no nível federal, incluindo a Corte de Tributos (Tax Court). Essas cortes se enquadram mais no Modelo 3 do que no Modelo 1.27 No nível da revisão judicial, a revisão aberta é incomum, porém eventualmente ocorre. Da mesma forma, há cortes especializadas que decidem casos originários de agências específicas, como, por exemplo, a Corte de Apelação para Causas de Militares Veteranos (Court of Appeals for Veterans' Claims) e a Corte de Apelação de Direitos Aduaneiros e de Marcas e Patentes (Court of Customs and Patent Appeals). Apesar dessas exceções, parece justo dizer que o Modelo 1 é o predominante no sistema de adjudicação administratia dos Estados Unidos.

25 ESTADOS UNIDOS. Suprema Corte. Caso Richardson v. Perales, 402 U.S. 389. Washington, 3 de maio de 1971. O julgamento Perales manteve os processos envolvendo incapacidade para fins de seguridade social sob a cláusula do devido processo e confirmou as múltiplas atribuições dos ALJs que atuam nessa área. A Corte não discutiu o APA, mas a decisão é compreendida como tendo confirmado o exercício de múltiplas funções pelos ALJs tanto sob o sistema do APA como sob a cláusula do devido processo.

26 Adjudicação a nível local normalmente não se enquadra no modelo mais usual nos EUA. Governos locais decidem uma grande quantidade de processos, envolvendo particularmente licenciamento, utilização do solo e questões ambientais. Frequentemente não há separação de poderes (muito menos separação de funções) a nível local. As audiências são frequentemente inquisitórias, ao invés de adversariais. A reconsideração pode ser exercida por órgãos com representação política (como Conselhos Municipais).

27 Em aproximadamente metade dos Estados surgiu um sistema híbrido, normalmente conhecido como "central panel". Em uma estrutura de central panel os HOs não trabalham para a agência de investigação e persecução. Os HOs (geralmente chamados de ALJs ou algum título semelhante) trabalham para uma agência separada (o central panel) e cada $\mathrm{HO}$ conduz as audiências e profere as decisões iniciais para várias agências. Nesse particular, a audiência inicial de julgamento é similar ao sistema de tribunal (discutido no Modelo 3). Todavia, nos sistemas de central panel o diretor da agência geralmente detém o poder de reconsideração, o que corresponde ao Modelo 1. 


\subsection{Modelo 2: Decisão inicial e recons'ideração inquisitórias - União Europeia}

Estados Membros da União Europeia (UE) fazem a adjudicação na maioria dos casos que dizem respeito aos seus programas de regulação e benefícios. Os sistemas de adjudicação administrativa empregados pela maioria dos países da Europa Continental se enquadram no Modelo 5. Todavia, a UE concentra as decisões de casos envolvendo assuntos específicos no nível da União, ao invés de deixá-los ao nível dos Estados membros. Essas hipóteses incluem concorrência, subsídios governamentais, marcas, segurança alimentar, regulação do comércio exterior e licenciamento de medicamentos. $A$ UE não tem um APA e o procedimento varia entre essas seis estruturas regulatórias. ${ }^{28}$

Ao nível da UE os processos de adjudicação (tanto a respeito da decisão inicial quanto da reconsideração) são inquisitórios, não adversariais. Por exemplo, em casos de concorrência e fusões, ${ }^{29}$ membros da equipe do Diretor Geral para Concorrência da Comissão Europeia (Director-General for Competition of the European Commission - DG-COMP) (aqui referidos como "encarregados do caso") conduzem uma investigação e subscrevem uma "declaração de objeções". Essa é a front-line decision (decisão preliminar). Na fase da decisão inicial, DG-COMP proporciona uma audiência para as empresas contra as quais a declaração de objeções é dirigida. O propósito da audiência é o de conferir aos particulares (investigados e demandantes) uma oportunidade para apresentarem seus pontos de vista acerca das questões e das provas que instruem o processo. A audiência é considerada como sendo parte da investigação, não uma fase separada. Os particulares não detêm o controle da audiência e não estão autorizados a formular perguntas às testemunhas da outra parte. A prevalência do modelo inquisitório no processo de elaboração de decisão administrativa de adjudicação não surpreende, dado que o procedimento criminal inquisitório é de uso praticamente universal na Europa. Após a audiência os encarregados do caso preparam uma decisão provisória. Ela é submetida a outros DGs para comentário, ao Departamento Jurídico da Comissão (Commission's Legal Service) e a um Comitê Consultivo, e deve ser revisada após o resultado dessas consultas.

A fase de reconsideração é conduzida pelo Colégio de Comissários da Comissão Europeia (College of Commissioners of the European Commission). O processo de reconsideração não inclui uma nova audiência, tampouco uma oportunidade para apresentação de novas provas. A UE emprega o sistema fechado de revisão judicial em cortes

28 ASIMOW, M. ; DUNLOP, L. The Many Faces of Administrative Adjudication in the European Union. Administrative Law Review, Washington, v. 61, p. 131-170, 2009.

29 A UE publicou um interessante manual retratando o procedimento nos processos envolvendo concorrência. EUROPEAN COMMISSION. Antitrust: Manual of Procedures. Bruxelas: European Commission Office, 2012. 
de competência comum (são eles, o Tribunal Geral e o Tribunal de Justiça da União Europeia).

No decorrer dos últimos trinta anos o procedimento inquisitório de elaboração das decisões iniciais no âmbito da UE experimentou uma interessante evolução. ${ }^{30}$ As cortes da UE criaram um leque de proteção para os particulares que segue o devido processo dos EUA e o sistema de "justiça natural" britânico, assegurando adequada ciência, uma audiência justa, acesso ao procedimento conduzido pela Comissão e direito de apresentação de suas razões. Essas inovações refletem um processo de evolução jurisprudencial do direito em grande parte sem apoio nos textos legais ou nos tratados. As decisões se parecem mais com o processo tradicional do common law dos EUA e do Reino Unido do que com o processo tradicional da civil law baseado em textos legais. Essas inovações ocorreram em grande parte por causa das objeções britânicas ao procedimento inquisitório da UE no momento da adesão pelo Reino Unido.31 Portanto, essas reformas processuais parecem ser um exemplo de transplante de institutos jurídicos do sistema adversarial do Reino Unido para o sistema inquisitório da UE. O rol de proteções de natureza processual construído pelas cortes da UE foi então incorporado à Carta Europeia de Direitos Fundamentais 32 e, por sua vez, ao Tratado da União Europeia. 33 Como resultado da incorporação das normas inerentes ao devido processo legal à sistemática de elaboração da decisão pela UE, as audiências nos casos de concorrência passaram a observar maior formalidade. Tradicionalmente as audiências eram conduzidas pelos case handlers (responsáveis do caso). De acordo com as regras atuais, todavia, o HO é um integrante do quadro da Comissão, e não mais o case handler. O HO não é contratado pelos acusadores (DG-COMP) e não está envolvido na investigação e persecução do caso. O HO organiza e conduz a audiência e decide questões sobre acesso ao material constante do processo preparado pelo DG-COMP. Em geral, a função do HO é assegurar que o interessado, oponente do DG-COMP, tenha um processo justo.

30 Ver CRAIG, P. EU Administrative Law. 2. ed. Nova York: Oxford University Press, 2012. cap. 12, 13; ASIMOW, M. ; DUNLOP, L. The Many Faces of Administrative Adjudication in the European Union. Administrative Law Review, Washington, v. 61, p. 143-155, 2009.

31 Ver BIGNAMI, F. Creating European Rights: National Values and Supranational Interests. Columbia Journal of European Law, Nova York, v. 11, p. 241-352, 2005.

32 Carta de Direitos Fundamentais da União Europeia, 2000 O. J. (C364), 18 de Dezembro de 2000, republicada com alteração em 2010 O. J. (C83) 389, 30 de Março de 2010. O Artigo 41 da Carta estabelece o direito a uma boa administração (right of good administration) significando que toda pessoa tem o direito de ter seus ou suas pretensões apreciadas com imparcialidade, justiça e dentro de um prazo razoável pelas instituições, funcionários, repartições e agências da União. Isso inclui o direito de ser ouvido, o direito de ter acesso aos autos do procedimento e a proteção da confidencialidade. Essa disposição da Carta sistematiza as decisões das Cortes Europeias que constroem a noção de direito ao devido processo no âmbito da adjudicação administrativa na Europa.

33 Versão consolidada do Tratado da União Europeia [Treaty on European Union], 2012 O. J. C 326/13 p. 391. 
Após a audiência, o HO apresenta um "relatório provisório" expressando conclusões no que diz respeito à efetiva observância das garantias processuais. $34 \mathrm{O} \mathrm{HO}$ pode também apresentar um relatório separado contendo observações no intuito do aprimoramento e da maior imparcialidade do processo, 35 e esse relatório pode conter recomendações substanciais a respeito das controvérsias de direito e de fato envolvidas no processo. $36 \mathrm{O}$ relatório final do $\mathrm{HO}$ é juntado à decisão inicial pelo DG-COMP, que é submetida ao Colégio de Comissários. Entretanto, o HO não profere uma decisão preliminar sobre o mérito do processo. Essa função permanece sendo atribuição dos case handlers. Por conseguinte, a introdução de um HO independente acarreta um grau limitado de separação de funções, mas não altera a natureza fundamentalmente inquisitória do processo de elaboração da decisão inicial nos casos relativos a investigação de práticas anticoncorrenciais.

No Modelo 2, se as principais controvérsias envolvidas no caso forem de natureza fática, a mais importante das três fases é a decisão inicial, e não a reconsideração ou a revisão judicial. ${ }^{37} \mathrm{~A}$ confiança dos Sindicatos na fase de decisão inicial tornou-se ainda mais evidente a partir da introdução das garantias do devido processo legal durante o processo inicial, particularmente com a utilização de HOs desvinculados da persecução nos processos envolvendo práticas anticompetitivas.

\subsection{Modelo 3: Tribunals - Reino Unido, Austrália}

O Modelo 3 descreve o sistema de adjudicação administrativa no Reino Unido (e em países cujos sistemas legais são derivados do Reino Unido, como Austrália ou Canadá). No Modelo 3 a decisão adjudicatória mais importante é proferida por um tribunal independente na fase de reconsideração.

No Reino Unido, agências de regulação ou de concessão de benefícios proferem as decisões iniciais. $38 \mathrm{O}$ requerimento inicial e a rejeição provisória de benefícios sociais são feitos on line. Aqueles que quiserem contestar essa front-line determination (decisão preliminar) podem requerer oralmente ou por escrito com uma exposição de motivos e solicitar que essa decisão seja revista por outro funcionário. ${ }^{39}$ Assim o processo de

34 Ver WILS, W. The Role of the Hearing Officer in Competition Proceedings Before the European Commission. World Competition: Law and Economics Review, [S.I.], v. 35, n. 3, p. 431-456, 2012.

35 WILS, W. Idem.

36 WILS, W. Idem.

37 Naturalmente, se as questões controvertidas envolvem questões de direito e não de fato, o que não é incomum em processos sobre práticas anticoncorrenciais, o estágio de revisão judicial poderá ser o mais importante dos três.

38 Eu agradeço a ajuda de Robert Thomas e Paul Craig acerca do procedimento no Reino Unido.

39 Ver CRAIG, P. Perspectives on Process: Common Law, Statutory and Political. Public Law, Londres, n. 2, p. 275 , 287-88, 2010. O Administrative Justice ; Tribunals Council emitiu um relatório analítico sobre a baixa qualidade na elaboração das decisões iniciais nas questões envolvendo seguro social: Right First Time (Junho de 2011). 
decisão inicial nas questões envolvendo a seguridade social é inquisitório, e não adversarial. Nos processos envolvendo regulação, o procedimento de elaboração da decisão inicial depende de leis e regulamentos específicos. $40 \mathrm{Em}$ geral, as regras de justiça natural dificilmente são aplicadas (ou pelo menos não são aplicadas com rigor) na fase de decisão inicial, desde que o governo propicie um processo pleno sobre o mérito na fase de reconsideração ou perante a corte judicial. 41

No Reino Unido, a reconsideração é praticada por um tribunal independente da agência que proferiu a decisão inicial. Tradicionalmente cada agência de regulação ou de concessão de benefício tinha seu tribunal correspondente. Por exemplo, um tribunal para questões envolvendo benefícios sociais ou imigração procedia à reconsideração das decisões iniciais proferidas segundo as leis da seguridade social ou de imigração. Os tribunals no Reino Unido empregam normalmente uma grande quantidade de juízes, muitos deles não sendo advogados. Os processos são apreciados por vários membros do tribunal em colegiado. As audiências nesses tribunals são essencialmente adversariais. ${ }^{42}$ Lei dos Tribunals e Inquéritos (The Tribunals and Inquiries Act - 1958) determinou que os tribunals apresentassem relatórios escritos e criou um Conselho dos Tribunals (Council on Tribunals) para realizar pesquisas e relatórios sobre o sistema de tribunals. 43 As decisões dos tribunals estavam sujeitas a recurso previsto em lei, bem como à revisão judicial segundo as regras da common law. Ambas as formas de revisão eram basicamente limitadas às questões de direito. 44

Em 2007, o Reino Unido aprovou a Lei de Tribunals, Cortes e Execução (Tribunals, Courts and Enforcement Act - TCEA), que promoveu uma ampla reestruturação no

Disponível em: <http://ajtc.justice.gov.uk/docs/AJTC_Right_first_time_web\%287\%29.pdf>. Ver THOMAS, R. Administrative Justice, Better Decisions, and Organizational Learning. Public Law, Londres, p. 111-131, 2015.

40 Ver GAROUPA, Nuno; OGUS, A.; SANDERS, Andrew. The Investigation and Prosecution of Regulatory Offenses: Is there an Economic Case for Integration. Cambridge Law Journal, Cambridge, v. 70, n. 1, p. 229-259, 2011. p. 238-40 (separação de funções na elaboração da decisão inicial nos processos envolvendo mercado financeiro).

41 Ver WADE, H.; FORSYTH, C. Administrative Law. 10th ed. Oxford: Oxford University Press, 2009. p. $442-44$.

42 Ver THOMAS, R. From "Adversarial v. Inquisitorial" to "Active, Enabling, and Investigative": Developments in UK Administrative Tribunals. In: JACOBS, L. ; BEGLAY, S. (Ed.). The Nature of Inquisitorial Processes in Administrative Regimes. Londres: Routledge, 2013. p. 51-70. Thomas menciona que os procedimentos variam entre os diferentes tribunals. Os procedimentos no âmbito da seguridade social tendem a ser mais inquisitórios, tendo em vista que a maioria dos particulares interessados e frequentemente o governo não estão representados por advogados. Procedimentos na área de imigração e de asilo alcançam um equilíbrio entre procedimento adversarial e procedimento inquisitório.

43 REINO UNIDO. Tribunals and Inquiries Act, 1958, 6 ; 7 Eliz. 2, c. 66.

44 O sentido da palavra "law" no âmbito da revisão judicial é muito amplo e inclui questões de aplicação do direito ao fato, relevantes erros de fato, pressupostos fáticos (jurisdictional fact) e abuso no exercício da discricionariedade. Em circunstâncias excepcionais fatos não apresentados durante a tramitação do procedimento administrativo podem ser levados em consideração pelas cortes. Ver WADE ; FORSYTH, nota 41, Ibid., p. 793800; CRAIG, P. Judicial Review, Appeal and Factual Error. Public Law, Londres, p. 788-807, 2004. 
sistema de tribunals. 45 TCEA reuniu a maioria dos tribunals e estabeleceu autonomia financeira para eles (anteriormente os tribunals eram financiados pelas agências cujos processos eles decidiam). O Tribunal de Primeiro Grau (First Tier Tribunal - FTT) exerce a reconsideração da maioria das decisões de agências. O FTT é dividido em seis "câmaras" especializadas em julgar processos envolvendo matérias específicas. 46

O Tribunal Superior (Upper Tribunal - UT) possui quatro "câmaras".47 O UT é definido em lei como uma corte superior e tem o poder de conceder variadas proteções judiciais. Portanto, o UT pode ser considerado como o responsável pela primeira (e geralmente a única) oportunidade de revisão judicial das decisões do FTT, e não como o responsável por um segundo nível de decisão em reconsideração. A revisão do UT é possível mediante admissibilidade prévia do FTT ou do UT, somente em relação a questões de direito que evoquem um importante princípio ou prática ou alguma outra razão que o justifique. Uma decisão do UT pode, por sua vez, ser objeto de recurso para a Corte de Apelação (Court of Appeal), mas apenas sobre uma importante questão de direito e ainda assim mediante admissibilidade prévia do UT ou da Corte de Apelação. 48 Também é possível a obtenção de revisão judicial fechada na Corte Superior (High Court) 49 contra a decisão da UT que não admitiu a apelação da decisão do FTT, mas, igualmente, só se o caso apresentar uma importante controvérsia jurídica. 50

O sistema tradicional australiano de adjudicação segue o modelo britânico. No estágio da decisão inicial, as agências australianas normalmente oferecem uma oportunidade de revisão por oficial que não esteve envolvido na investigação. Esse processo de revisão normalmente oferece ao particular uma oportunidade para apresentação de alegações escritas e, por vezes, um contato pessoal ou telefônico entre o particular e o oficial encarregado da revisão. 51

45 Ver WADE; FORSYTH. Op. cit. p. 776-83.

46 REINO UNIDO. Ministry of Justice. About Tribunals, Londres, 2012, Disponível em: <http://www.justice.gov. uk/about/hmcts/tribunals>. Acesso em: 17 nov.2016. Regulamentos estabelecem os procedimentos a serem seguidos pela FTT. Ver CRAIG, P. Perspectives on Process: Common Law, Statutory and Political. Public Law, Londres, n. 2, p. 289-93, 2010.

47 REINO UNIDO. Op cit.

48 Ver ELLIOTT, M. Ombudsmen, Tribunals, Inquiries: Re-Fashioning Accountability Beyond the Courts. Legal Studies Research Papers Series, Cambridge, n. 21, 2012.

49 Ver WADE, H.; FORSYTH, C. Administrative Law. 10th ed. Oxford: Oxford University Press, 2009. cap. 18. Para obter-se a revisão judicial, é necessário primeiro assegurar-se da permissão para chegar até lá. Os juízes da High Court que exercem a revisão judicial dos atos das agências são conhecidos como a Corte Administrativa.

50 Ver REINO UNIDO. Suprema Corte. Caso R. (Cart) v. Upper Tribunal UKSC 28. Londres, 22 de Junho de 2011; ELLIOTT, Mark; THOMAS, Robert. Tribunal Justice, Cart, and Proportionate Dispute Resolution. Cambridge Law Journal, Cambridge, v. 71, n. 2, p. 297-324, 2012. p. 297. A revisão judicial na Corte Administrativa também é possível, obviamente, nas causas entre os particulares e o governo para as quais não haja possibilidade de recurso para um tribunal.

51 ASIMOW, Michael ; LUBBERS, Jeffrey S. The Merits of "Merits" Review: A Comparative Look at the Australian Administrative Appeals Tribunal. Windsor Yearbook of Access to Justice, Ontário, v. 28, p. 261-284, 2010. p. 263. 
Essas decisões iniciais são submetidas à reconsideração por tribunals. Tradicionalmente, a Austrália tinha um tribunal separado para cada agência. Em 1976 ela fundiu todos eles em um único, conhecido como Tribunal de Apelações Administrativas ( $A d$ ministrative Appeals Tribunal - AAT).52 O AAT proporciona audiências de reconsideração quase judiciais (também chamadas revisão do mérito) para mais de 400 agências. ${ }^{53}$ Em alguns casos, incluindo seguridade social, benefícios para veteranos de guerra e imigração, existem tribunals especializados; o AAT então oferece um segundo nível de reconsideração para algumas decisões desses tribunais especializados. As decisões do AAT podem ser objeto de recurso para a Corte Federal (Federal Court), mas somente versando sobre questão de direito.

O Reino Unido e a Austrália investem a maior parte dos recursos destinados à adjudicação no processo de reconsideração a cargo dos tribunals. Esse é o nível no qual os particulares creditam as melhores chances de obtenção de um resultado favorável. Ao nível da decisão inicial da agência, existem algumas condições de procedibilidade; ao nível de revisão judicial, o seu estreito escopo impede as cortes de acolherem recursos jurídicos na maioria dos casos envolvendo controvérsia sobre fatos ou sobre o exercício do poder discricionário. Com efeito, no Reino Unido, o UT aparenta ter substituído quase integralmente a revisão judicial nas cortes de competência comum.

\subsection{Modelo 4: Revisão Judicial Aberta - China, Argentina e Japão}

No Modelo 4, o processo de elaboração da decisão inicial e de reconsideração é relativamente desestruturado. As agências podem proporcionar uma audiência informal ou, ao menos, um encontro entre o particular interessado e o corpo funcional da agência, bem como oferecer uma oportunidade de reconsideração perante um nível hierárquico superior. No entanto, a decisão importante ocorre em um processo judicial aberto. Quando um país admite revisão judicial aberta, é como se ele tivesse escolhido investir seus recursos mais vultosos na fase da revisão judicial, e não nas fases de decisão inicial e de reconsideração. A presunção subjacente é de que os procedimentos administrativos anteriores à revisão judicial não teriam esgotado as provas dos fatos alegados; e essa atribuição seria de responsabilidade da corte de revisão. China, Argentina e Japão são exemplos de países que empregam variações do Modelo 4.

$\mathrm{Na}$ China, ${ }^{54}$ as agências dos governos central, provincial e local proferem um grande número de decisões de adjudicação. A legislação chinesa recente oferece

52 Ibid., p. 263-67.

53 O ATT pode até considerar prova de fatos ocorridos após a decisão inicial. Ver ALLARS, Margaret. The Nature of Merits Review: A bold vision realised in the administrative appeals tribunal. Federal Law Review, Canberra, v. 41, n. 2, p. 197-226, 2013.

54 Manifesto minha estima a Jin Weifeng, Wang Xixin, Zhou Hanhua e He Haibo pela ajuda com o direito administrativo chinês. 
garantias processuais em todos os três níveis - decisão inicial, reconsideração e revisão judicial. 55 Entretanto, na prática, somente um número relativamente pequeno das pessoas que são prejudicadas pelas decisões das agências se valem de algum desses expedientes; a maioria recorre a um informal, porém bem organizado "procedimento de peticionamento" ("xinfang", algumas vezes chamado "cartas e visitas") perante oficiais que sempre existiram na história chinesa, mas que são ineficazes para a obtenção de reparação pelos indivíduos que tenham sido prejudicados por alguma conduta ilegal do governo. 56

A Lei de Sanções Administrativas de 1996 (Administrative Penalty Law -APL) 57 é aplicável à fase de decisão inicial. Ela determina que agências central e local respeitem as garantias de um processo justo quando impuserem sanções. Para tal finalidade, as sanções abrangem as advertências disciplinares, multas, confiscos, suspensões ou rescisões de permissões ou licenças e detenções administrativas. O APL dispõe que as pessoas que estão sujeitas à imposição de penalidades devem ser adequadamente cientificadas e devem ter o direito de expor seus casos e também de defenderem-se. A agência deve abster-se de impor uma sanção mais grave pelo simples fato de os interessados terem exercido seu direito de defesa. ${ }^{58} \mathrm{Na}$ hipótese de penalidades graves (como, por exemplo, multas elevadas ou revogações de licença), deve haver uma audiência pública presidida por uma pessoa distinta daquela que conduziu a investigação. 59

55 Complementando as leis resumidamente apresentadas neste texto, a China editou um Administrative Licensing Law (2004) e um Administrative Enforcement Law (2011), os quais visam assegurar garantias adicionais no estágio da decisão inicial.

56 Ver MINZNER, C. Xinfang: Alternative to Formal Chinese Legal Institutions. Stanford Journal International Legal, Stanford, v. 42, p. 103-179, 2006. Existem vários serviços de Xinfang na China que recebem reclamações de cidadãos e há minuciosas regulamentações que descrevem como o sistema deveria funcionar. O Xinfang possui várias funções além da reivindicação de direitos, como, por exemplo, fornecer informações aos funcionários do governo acerca de corrupção ou outros abusos a nível local. Minzner estima que o sistema Xinfang recebe aproximadamente 11,5 milhões de requerimentos por ano, perto de 100 vezes mais do que os 125.000 casos que são apresentados de acordo com o procedimento estabelecido no Administrative Litigation Law. Todavia, somente uma minúscula porcentagem dos requerentes alcança resultado favorável através do Xinfang. Ibid., p. 105-06 (relatando que apenas 0,2\% dos reclamantes conseguem resultado favorável através de suas petições). Alterações agora em estudo na China devem vedar o acesso ao procedimento Xinfang para os requerentes cujos casos poderiam ser submetidos sob o regramento do Administrative Reconsideration Law, nota 60, ou sob o Administrative Litigation Law, nota 63.

57 Xingzheng Chufa Fa [Lei da República Popular da China sobre Sanções Administrativas] (promulgada pela Ordem n 63 do Presidente da República Popular da China, 17 de Março de 1996, vigente em $1^{\circ}$ de Outubro de 1996), disponível em inglês em: <http://www.china.org.cn/english/government/207306.htm>. Acesso em: 11 nov. 2016 [doravante Administrative Penalty Law].

58 Arts. 6, 8, 31-32 da Lei da República Popular da China sobre Sanções Administrativas [Administrative Penalty Law].

59 Ibid., p. 39, 42. Se as agências dos governos locais realmente obedecem a esses requisitos na prática é outra questão. Muitos professores renomados sustentam que um APA abrangente é necessário em razão de as garantias processuais atualmente reconhecidas não estarem sendo levadas a sério pelas agências governamentais ou mesmo pelas cortes. SONGNIAN, Y. ; XIXIN, W. Between Dreams and Reality: Making of the Administrative Procedure Act in China, [S.I.], p. 8-9, 2012 (artigo publicado em chinês; versão em Inglês arquivada com o autor). 
Segundo a Lei sobre Reconsideração Administrativa de 1999 (Administrative Reconsideration Law - ARL),60 a parte interessada tem o direito de pleitear a reconsideração de vários tipos de decisões desfavoráveis das agências (não somente penalidades) perante um superior hierárquico da mesma agência que proferiu a decisão inicial.61 Os responsáveis pela análise do pedido de reconsideração podem determinar a produção de prova e devem examinar os autos do processo. Eles devem ouvir as alegações do demandante, da agência e de terceiros interessados. A agência demandada deve justificar seus atos e o demandante tem o direito de obter uma cópia desse documento de justificativa. A agência incumbida da reconsideração deve reformar a decisão se "os fatos principais não estiverem claros e a prova essencial for inadequada" por causa de um erro de direito (erro jurídico) ou pela violação de procedimentos estabelecidos, ou ainda em razão de "o ato ser manifestamente inapropriado". A reconsideração é isenta de custas.62

Finalmente, a Lei do Contencioso Administrativo de 1989 (Administrative Litigation Law - ALL) 63 contempla os interessados com uma proteção judicial para praticamente todos os atos decisórios das agências que lhes sejam desfavoráveis. ${ }^{64}$ Conforme estabelecido no ALL, uma corte de competência comum conduz um julgamento inquisitório e aberto acerca das questões que envolvem o caso. Os juízes não devem estar sujeitos a interferência externa de ninguém. A agência governamental tem o ônus da prova. Normalmente os julgamentos são abertos ao público e neles há um colegiado

60 Xingzheng Fuyi Fa [Lei da República Popular da China Sobre Reconsideração Administrativa] (promulgada pela Ordem No. 16 do Presidente da República Popular da China, 29 de Abril de 1999, vigente em $1^{\circ}$ de Outubro de 1999), disponível em inglês em: <http://www.npc.gov.cn/englishnpc/Law/2007-12/11/content_1383562. htm > [doravante Administrative Reconsideration Law].

61 O ARL se aplica a decisões relativas aos recursos naturais e do solo, infrações administrativas no exercício do poder decisório, reclamações contra cobrança ilegal de fundos ou de impostos sobre a propriedade, indeferimento de permissões ou licenças, descumprimento de obrigações legais de proteção a direitos individuais referentes às pessoas, propriedade ou educação e descumprimento da obrigação de conceder uma pensão ou outro benefício social. Ibid., art. 6 . Ele também abrange os ataques à legalidade de regras informais da agência que compõem a base do ato impugnado. Ibid., art. 7. Ver WEI CUI. Foreign Administrative Law and International Taxation: A Case Study of Treaty Implementation in China. Administrative Law Review, Washington, v. 64, p. 191-233, 2012.

62 Arts. 3, 22-23, 28, 39 da Lei sobre Reconsideração Administrativa [Administrative Reconsideration Law of people's Republic of China de 1999].

63 Xingzheng Susong Fa [Administrative Litigation Law da República Popular da China] (promulgado pela Ordem no 16 do Presidente da República Popular da China em 4 de Abril de 1989, vigente em $1^{\circ}$ de Outubro de 1990), disponível em inglês em: <http://www.china.org.cn/english/government/207335.htm> [doravante Administrative Litigation Law]. O ALL também é conhecido como Administrative Procedure Law.

64 Para compreensão da história do ALL ver PALMER, Michael. Compromising Courts and Harmonizing Ideologies: Mediation in the Administrative Chambers of the People's Republic of China In: HARDING, A.; NICHOLSON, P. (Ed.). New Courts in Asia. Londres \& Nova York: Routledge, 2010. p. 251. 
de juízes ou de juízes e avaliadores.65 A corte tem o poder de alterar as conclusões da agência sobre fatos e determinações discricionárias. 66

O ALL representa um grande passo rumo ao Estado de Direito na China. ${ }^{67}$ Ele é particularmente notável considerando o histórico de pouca tolerância com desafios à autoridade da China confucionista e maoísta.68 O ALL representa um significativo comprometimento dos recursos judiciais. Aproximadamente 125.000 casos por ano são propostos com base no ALL e cerca de dez a vinte por cento resultam em uma decisão favorável ao autor particular. 69 O governo central começou a financiar cortes locais, o que deve reforçar a independência judicial.

Todavia, o direito descrito nos livros é diferente do direito aplicado na vida real quando se trata da revisão judicial dos atos das agências com fundamento no ALL. ${ }^{70}$ Muitos juízes chineses possuem baixa qualificação, embora a qualidade do Judiciário esteja aumentando regularmente. É difícil para os demandantes obterem representação jurídica nos processos submetidos ao rito do ALL, e as cortes são, por vezes, relutantes em admitir os casos submetidos ao ALL ou mesmo pronunciar-se sobre eles, principalmente se as questões envolvidas forem tidas como politicamente sensíveis. Às vezes os juízes, ao decidirem casos específicos, são sujeitos à influência do governo local ou do Partido Comunista.71 Julgamentos contrários ao governo são difíceis de

65 Arts. 3, 11, 30-32, 45-46 da Lei do Contencioso Administrativo de 1989 [Administrative Litigation Law].

66 Ibid., arts. 54(2)(a) e (e) estabelecem que a Corte pode anular uma decisão por insuficiência de prova essencial ou abuso de poder, bem como por inobservância de procedimentos estabelecidos em lei ou regulamentos. Tenho informações de que a insuficiência da prova é a base legal mais frequentemente citada como causa para a invalidação dos atos da Administração. Email de He Haibo. Publicação eletrônica [mensagem pessoal]. Mensagem recebida pelo autor em 6 nov. 2012.

67 Ver MAHBOUBI, N. Suing the Government in China. In: ZHOU, K.; RIGGER, S.; WHITE III, L. (Ed.). Democratization in China, Korea, and Southeast Asia. Londres: Routledge, 2014. p. 141-155. Mahboubi comenta que apesar do seu potencial não realizado, o ALL trouxe importantes consequências, incluindo as leis processuais subsequentes discutidas supra nos textos das notas 57-62 e as inovações processuais nos níveis locais. Ele também argumenta que o contencioso administrativo oferece um espaço para disputas adversariais entre os cidadãos e o governo, chama a atenção para falhas específicas da administração e encoraja a formação de grupos de interesse formados por partes e advogados.

68 GINSBURG, Tom. Confucian Constitucionalism? Globalization and Judicial Review in Korea and Taiwan. Law and Social Inquiry, [S.I.], v. 27, n. 4, p. 763-799, 2002. p. 763.

69 Em aproximadamente 30 a 40 por cento dos processos os autores desistem da ação antes da decisão judicial. Algumas desistências são forçadas, mas em muitos casos as partes desistem por terem negociado um acordo. Ver HE HAIBO. Litigation Without a Ruling: The Predicament of Administrative Law in China, Tsinghua China Law Review, Pequim, v. 3, p. 257-280, 2011.

70 Ver K KINKEL, Jonathan ; HURST, William. Review Essay - Access to Justice in Post-Mao China: Assessing the Politics of Criminal and Administrative Law. Journal of East Asian Studies, Cambridge, v. 11, n. 3, p. 467-499, 2011. 479-488; MAHBOUBI, N. Suing the Government in China. In: ZHOU, K.; RIGGER, S.; WHITE III, L. (Ed.). Democratization in China, Korea, and Southeast Asia. Londres: Routledge, 2014. p. 141-155.

71 Ver PEERENBOOM, R. Judicial Independence in China: Lessons for Global Rule of Law Promotion. Nova York: Cambrigde University Press, 2010. Os ensaios desse livro enfatizam que houve progressos na direção da garantia da independência judicial na China. O grau de independência é variável entre os diferentes tipos de casos. Ver particularmente o ensaio de PEERENBOOM, Randall. Judicial Independence in China: Common 
executar. Oficiais do Partido tornaram-se cautelosos no cumprimento de decisões judiciais sobre normas de direito administrativo e têm procurado substituir as decisões de adjudicação pela mediação. Retaliações contra demandantes praticadas por oficiais processados não são incomuns. ${ }^{72}$

O sistema argentino é basicamente similar ao da China. ${ }^{73}$ No nível da decisão inicial, a Lei do Procedimento Administrativo argentino ${ }^{74}$ determina que o particular deve ter o direito de vista dos autos do procedimento administrativo, de apresentar alegações escritas e provas e de receber uma decisão fundamentada, mas normalmente não há audiência. $O$ diretor da agência (normalmente um gabinete ministerial) tem a atribuição de exercer a reconsideração mediante requerimento escrito.

A decisão ministerial está sujeita à revisão judicial aberta em uma corte federal ou provincial de competência comum. ${ }^{75} \mathrm{~A}$ corte decide com independência as questões de direito, de fato e aquelas referentes ao poder discricionário, sem guardar deferência à decisão ministerial. Obviamente, o processo de revisão judicial aberta dos atos administrativos exige um significativo investimento de recursos. Na Argentina, a revisão judicial é o nível mais importante, e não as fases de decisão inicial e de reconsideração, na visão dos advogados públicos e dos advogados privados.

O Japão também segue o Modelo 4.76 Entretanto, em virtude da baixa quantidade de processos nos quais se busca a revisão judicial (somente poucos milhares por ano em uma nação de 127 milhões de pessoas) parece duvidoso que os particulares e os advogados identifiquem a revisão judicial como a mais importante das três fases

Myths and Unfounded Assumptions. La Trobe Law School Legal Studies Research Paper, Melbourne, $\mathrm{n}^{\circ} 11$, sept. 2008. Disponível em: < http://bit.ly/2fLYxZW>. Acesso em: 11 nov. 2016.

72 Ver MINZNER, C. China's Turn Against Law. American Journal of Comparative Law, [S.I.], vol. 59, p. 935-984, 2011.

73 Ver BALBIN, C. F. Manual de Derecho Administrativo. Buenos Aires: La Ley, 2011. Eu agradeço a ajuda sobre o direito argentino recebida de Juan Cruz Azzari, Hector Mairal, Laura Monti, Joaquin Villegas e outros professores argentinos.

74 Lei do Procedimento Administrativo argentino [Ley de procedimiento administrativo[22] B.O. 411] / Lei $\mathrm{n}^{\circ}$ 19549, 27 de Abril de 1972.

75 A Argentina possui tribunals especializados que fazem a reconsideração em processos envolvendo tributos e serviço público; quando uma decisão de um tribunal especializado é objeto de recurso perante uma corte a revisão é fechada, e não aberta. Na área de Buenos Aires, alguns juízes são especializados em direito administrativo, muito embora eles sejam integrantes de uma corte de competência comum.

76 O Administrative Procedure Law do Japão (Gyôsei Tetsuzuki-hõ, Lei № 88 de 1993, disponível em inglês em: <http://www.cas.go.jp/jp/seisaku/hourei/data/APA_2.pdf>) disciplina as audiências administrativas e o Administrative Appeals Law (Gyôsei fufuku shinsa-hõ?, Lei № 160 de 1962) disciplina a reconsideração. Cortes de competência comum fazem uma revisão judicial aberta em relação às questões de fato, porém somente anulam atos discricionários se ficar constatado que houve abuso no exercício do poder discricionário. Ver GINSBURG, Tom. Dismantling the "Developmental State?" Administrative Procedure Reform in Japan and Korea. The American Journal of Comparative Law, Chicago, v. 49, n. 4, p. 585-625, 2001. p. 599-606; USHIJIMA, H. Administrative Law and Judicialized Governance in Japan. In: GINSBURG, Tom ; CHEN, Albert H.Y. (Eds.). Administrative Law And Governance In East Asia. Londres: Routledge, 2009. p. 81-100; RAMSEYER, M.; NAKAZATO, M. Japanese Law: An Economic Approach. Chicago: The University of Chicago Press, 1999. cap. 8. Meus agradecimentos a Tsuyashi Koshikawa, Mark Ramseyer e Joel Rheuban pela ajuda em Direito Administrativo japonês. 
da adjudicação. ${ }^{77}$ As reduzidas chances de sucesso, combinadas com os altos custos do processo e uma escassez de advogados e juízes provavelmente explica porque tão poucos possíveis litigantes no Japão se dão ao trabalho de desafiar as decisões burocráticas perante as cortes. Devem também existir fatores culturais em jogo que desencorajam as pessoas de processar o governo no Japão. Todavia, a estimativa atual (em torno de 4.000 processos por ano) representa um substancial aumento em relação aos anos de 1986 a 1995, quando somente poucas centenas de processos eram ajuizados a cada ano.78

\subsection{Modelo 5: Revisão judicial em cortes especializadas - França e Alemanha}

Um número de países admite revisão judicial aberta dos atos de agência perante um sistema especializado de cortes administrativas. ${ }^{79}$ França e Alemanha servem como os principais exemplos de sistemas de cortes administrativas. 80 Esses sistemas lidam com uma substancial quantidade de processos por ano, o que sugere que eles são considerados pelo público e pelos advogados como o mais importante dos três níveis da adjudicação. 81

\footnotetext{
77 Somente um número em torno de 2.000 a 4.000 processos envolvendo matéria administrativa são julgados anualmente pelas cortes de competência comum que exercem revisão judicial aberta. Apenas cerca de dez por cento dos autores conseguem ter êxito. Ver USHIJIMA. Op cit. p. 92 . Em 2006 havia 2.093 casos novos e 2.565 foram decididos. Em 2012 os números subiram levemente -4.783 processos novos, 4.840 decididos. Ver NEMPO, S.T. [Relatório Anual de Estatísticas Judiciais], tbl. 4, [S.I.], 2012.

78 Ver RAMSEYER, M.; NAKAZATO, M. Japanese Law: An Economic Approach. Chicago: The University of Chicago Press, p. 219, 1999. O aumento poderia ser explicado por uma alteração ocorrida em 2004 no Administrative Case Litigation Law, Gyõsei jiken soshõ-hõ, Lei № 139 de 1962 (disponível em inglês em: <http://www.japaneselawtranslation.go.jp/law/detail/?id=1922;vm=04;re=02>. Acesso em: 17 nov. 2016), que permite a utilização de uma ação declaratória contra orientações administrativas. $O$ aumento dos casos de envolvendo a matéria administrativa reflete um pequeno aumento na quantidade de processos judiciais de natureza cível no Japão, que pode ser atribuído principalmente a um aumento da quantidade de advogados e juízes e à desaceleração econômica. Ver GINSBURG, T.; HOETKER, G. The Unreluctant Litigant? An Empirical Analysis of Japan's Turn to Litigation. Journal of Legal Studies, Chicago, v. 35, n. 1, p. 31-59, 2006.

79 Existe uma posição intermediária entre realizar a revisão judicial dos atos da administração em cortes de competência comum ou em cortes especializadas na matéria administrativa. Alguns países instituíram cortes especializadas em direito administrativo dentro do sistema judicial comum, no entanto as decisões dessas cortes são revistas por cortes de apelação de competência comum, e não por cortes de apelação especializadas em direito administrativo.

80 Para uma análise comparada das cortes administrativas ver BIGNAMI, F. From Expert Administration to Accountability Network: A New Paradigm for Comparative Administrative Law. American Journal of Comparative Law, Washington, v. 59, n. 4, p. 891-886, 2011.

$81 \mathrm{Na}$ França, aproximadamente 175.000 processos são levados à corte administrativa a cada ano (com uma taxa de sucesso de vinte e quatro por cento). Na Alemanha, aproximadamente 125.000 processos são levados à corte administrativa a cada ano (com uma taxa de sucesso de vinte e seis por cento). Ver ASSOCIATION OF THE COUNCILS OF STATE AND SUPREME ADMINISTRATIVE JURISDICTIONS OF THE EUROPEAN UNION I.N.P.A., TOUR OF EUROPE.
} 
Em um sistema de cortes administrativas especializadas, as partes têm acesso a um conjunto de juízes que são especialistas na solução de controvérsias envolvendo direito administrativo e sensíveis a potenciais abusos da burocracia. Ao que parece, a existência de um sistema de corte administrativa especializada aplicando revisão aberta induz um maior número de recursos do que haveria se a revisão fosse fechada ou se fosse realizada por cortes de competência comum. Em relação aos custos, a decisão de instituir um sistema de cortes especializadas exige o dispêndio de recursos econômicos (como uma nova infraestrutura) que poderiam ser desnecessários se as cortes de competência comum revisassem os atos das agências. Além disso, havendo um sistema dual de cortes (administrativa e geral) é possível a ocorrência de problemas envolvendo o estabelecimento de qual delas teria competência sobre determinados tipos de casos, necessitando desse modo de algum mecanismo para a solução de conflitos de competência.

Na França, no nível da decisão inicial, as agências são obrigadas a oferecer um processo justo antes da adoção de uma ação "negativa". Os procedimentos utilizados são de natureza inquisitória e incluem pelo menos uma ciência adequada, o direito de apresentação de defesa escrita e uma decisão fundamentada. 82 Dependendo da questão envolvida, a decisão inicial pode ser reconsiderada por um oficial de nível hierárquico superior. O sistema de corte administrativa da França é parte integrante do Executivo e não do Judiciário.83 Ele teve origem na Revolução Francesa e reflete a ideia de que o Executivo não deveria ficar submetido ao controle do Judiciário. Existem trinta e oito cortes administrativas. Acima delas existem oito cortes administrativas de apelação e acima dessas está o Conselho de Estado, que é a Corte Suprema da França para as causas de direito administrativo. O modelo de corte administrativa francês foi adotado por vários outros países europeus, africanos e asiáticos.

82 Ver AUBY, J.-B. ; CLUZEL-M'ETAYER, L. Administrative Law in France. In: SEERDEN, R. (Ed.). Administrative Law of The European Union, Its Member States and The United States. 2. ed. Cambridge: Intersentia, 2007. p. 61 ; 68; SCHWARTZ, B. French Administrative Law And The Common Law World. New York: New York University Press, 1954. p. 207-11; CE Sect., 5 de Maio de 1944, Rec. Lebon 133 (a revogação de uma licença para publicação de um jornal em razão de conduta imprópria exige que a Administração providencie a ciência do interessado e uma audiência), traduzido para o inglês como "Widow Trompier-Gravier" em SCHWARTZ. Op cit. p. 324-44.

83 Ver MASSOT, J. The Powers and Duties of the French Administrative Law Judge. In: ROSE-ACKERMAN, S.; LINDSETH, P. (Eds.). Comparative Administrative Law, Cheltenham: Edward Elgar Publishing, 2010. p. 415425; AUBY, J.-B. ; CLUZEL-M'ETAYER, L. Administrative Law in France. In: SEERDEN, R. (Ed.). Administrative Law of The European Union, Its Member States and The United States. 2. ed. Cambridge: Intersentia, 2007. p. 61 ; 68. Os juízes administrativos na França exercem atividade consultiva para o governo na elaboração da legislação e regulamentos e publicam seus trabalhos com propostas de melhorias para o processo administrativo. Como as cortes administrativas francesas estão situadas dentro do Poder Executivo, o termo "judicial review" é provavelmente inaplicável, mas eu me mantive preso a ele; as cortes administrativas francesas certamente atuam mais como cortes judiciais do que como julgadores administrativos. Meus agradecimentos a Thomas Perroud e a John Bell pela ajuda com o direito administrativo Francês. 
As cortes administrativas francesas têm a prerrogativa de determinar que as partes apresentem provas ou esclarecimentos adicionais, logo a revisão é aberta ao invés de fechada. As cortes administrativas frequentemente reformam decisões administrativas com base em revisão não deferente às interpretações de lei procedidas pelas agências e por erro manifesto acerca dos fatos ou da discricionariedade ou por violação ao princípio da proporcionalidade. 84 Nos processos envolvendo aplicação de sanções, como no exemplo da exploração do serviço de balsas, 85 as cortes fazem "revisão judicial plena", o que significa dizer revisão totalmente aberta e o poder de substituir o julgamento quanto a questões de fato e de discricionariedade. 86

As cortes administrativas alemãs estão inseridas no Poder Judiciário e não no Executivo.87 A versão atual da Lei alemã de Procedimento Administrativo foi promulgada em 1976, mas suas origens datam da época de 1860.88 Quanto à fase de decisão inicial, a Lei alemã estabelece um procedimento inquisitório, que inclui uma possibilidade de ter vista dos autos e de apresentação de razões. A agência deve apresentar sua fundamentação. 89 Antes de requerer a revisão judicial, o particular deve tentar a reconsideração administrativa perante um nível hierárquico superior da agência; as autoridades responsáveis pela reconsideração devem analisar a correção da investigação dos fatos, assim como do exercício da discricionariedade na fase de decisão inicial.90

O sistema alemão de cortes administrativas prevê a possibilidade de revisão judicial aberta dos atos administrativos. A corte administrativa conduz uma audiência de

84 JORDÃO, E.; ROSE-ACKERMAN, S. Judicial Review of Executive Policymaking in Advanced Democracies Beyond Rights Review. Administrative Law Review, Washington, v. 66, n. 1, p. 29-38, 2014 (padrão geral de revisão não deferente pelas cortes administrativas francesas); AUBY, J.-B.; CLUZEL-M'ETAYER, L. Administrative Law in France. In: SEERDEN, R. (Ed.). Administrative Law of The European Union, Its Member States and The United States. 2. ed. Cambridge: Intersentia, 2007. p. 78; BROWN, L. N.; BELL, J. S. French Administrative Law. Toronto: Oxford University Press, 5. ed., 1998. p. 261-67.

85 Ver texto da nota 8.

86 Essas sanções são consideradas quase criminais e invocam o direito a um tribunal independente e imparcial consoante o Artigo 6(1) da Convenção Europeia dos Direitos Humanos (que abrange a fixação de direitos civis e obrigações, assim como imputações criminais). Ver CONSEIL D'ÉTAT ASSEMBLÉE, 16 de Fevereiro de 2009, Rec. Lebon, Req. № 274000 (Société ATOM) (sustentando que a CEDH determinou uma ampla revisão judicial em um caso envolvendo multas fiscais).

87 Agradeço a ajuda de Hermann Pünder nos temas de direito administrativo Alemão.

88 Ver BIGNAMI, Francesca. From Expert Administration to Accountability Network: A New Paradigm for Comparative Administrative Law. American Journal of Comparative Law, Washington, v. 59, n. 4, p. 859-908, 2011. p. 895; SCHRÖDER, M. Administrative Law in Germany. In: SEERDEN, R. (Ed.). Administrative Law of The European Union, Its Member States, and The United States. 2. ed. Cambridge: Intersentia, 2007. p. 91-154. AUBY, J.-B.; CLUZEL-M’ETAYER, L. Administrative Law in France. In: SEERDEN, R. (Ed.). Administrative Law of The European Union, Its Member States and The United States. 2. ed. Cambridge: Intersentia, 2007. p. 94.

89 Ver SCHRÖDER. Op cit. p. 123-26; ALEMANHA. Verwaltungsverfahrensgesetz [VwVfG] [Administrative Procedure Act], 25 de Maio de 1976, BUNDESGESETZBLATT [BGBL.] Disponível em inglês em: <http://www.iuscomp. org/gla/statutes/VwVfG.htm>. Acesso em: 17 nov. 2016.

90 SCHRÖDER. Op cit. p. 125, 138-139; Verwaltungsgerichtsordnung [VwGO] [Code of Administrative Court Procedure], 19 de Março de 1991, BGBL. Disponível em inglês em: <http://www.gesetze-im-internet.de/englisch_vwgo/englisch_vwgo.html>. Acesso em: 17 nov. 2016. 
instrução e deve oferecer uma detalhada decisão sobre o mérito, com os respectivos fundamentos. Ela pode geralmente substituir, com suas decisões, as conclusões das agências (particularmente as conclusões relativas a conceitos jurídicos indeterminados) e podem invalidar os atos administrativos discricionários por abuso no exercício da discricionariedade ou porque os atos não passam no teste de proporcionalidade. ${ }^{91}$ Existem três níveis no sistema de cortes administrativas - cortes administrativas, cortes administrativas superiores e a Corte Federal Administrativa. A revisão ao nível da Corte Federal Administrativa ocorre apenas em processos nos quais há dúvida sobre a correção do julgamento ou se a causa apresenta dificuldades incomuns. O modelo alemão tem sido transplantado para vários países europeus e latino-americanos. ${ }^{92}$

\section{AVALIANDOETRANSPLANTANDO SISTEMAS DE ADJUDICAÇÃO}

Este artigo é descritivo, não é normativo. Ele não adota uma posição sobre qual é o modelo ideal. Em minha opinião, cada um dos modelos pode alcançar um equilíbrio apropriado entre três elementos habitualmente usados para avaliar práticas ou instituições de direito administrativo: precisão (significando que os julgadores provavelmente chegarão ao resultado correto), eficiência (significando que o sistema deve minimizar a demora e os custos para os setores público e privado) e justiça (significando que o sistema deve ser aceitável para aqueles que são por ele afetados).93 Todos eles podem atingir os padrões do direito a uma boa administração, conforme estabelecido na Carta de Direitos Fundamentais da União Europeia. ${ }^{94} \mathrm{Um}$ bom sistema de adjudicação administrativa é acessível a pessoas comuns, mesmo para aquelas sem representação jurídica. O quadro responsável por cada uma das decisões - inicial, reconsideração e judicial - deve ser adequadamente financiado e preenchido por oficiais que sejam capazes e independentes. Um bom sistema proporciona decisões em tempo razoável e a um custo moderado para o governo e para os particulares. Cada um dos cinco modelos pode atender a esses padrões.

\footnotetext{
91 ALEMANHA. VwGO [Código de Processo da Corte Administrativa] § 114. Ver HERBERT, G. Administrative Justice in Europe - Report for Germany [S.I.: n.d.]; SCHRÖDER, M. Administrative Law in Germany. In: SEERDEN, R. (Ed.). Administrative Law of The European Union, Its Member States, and The United States. 2. ed. Cambridge: Intersentia, 2007. p. 128-142, 132; SINGH, M. P. German Administrative Law in Common Law Perspective. 2. ed., v. 149. Berlin: Springer, 2001. p. 223-32, 242-43. Conforme relato de Singh, aparentemente as cortes [Administrativas] estão fazendo um bom trabalho e as pessoas parecem estar bastante satisfeitas com a simplicidade, conveniência, adequação e efetividade dos procedimentos perante elas.

92 BIGNAMI, Francesca. From Expert Administration to Accountability Network: A New Paradigm for Comparative Administrative Law. American Journal of Comparative Law, Washington, v. 59, n. 4, p. 859-908, 2011. p. 896.

93 Ver CRAMTON, Roger. A Comment on Trial-Type Hearings in Nuclear Power Plant Siting. Virginia Law Review, Charlottesville, v. 58, n. 4, p. 585-599, 1972. Disponível em: < http://bit.ly/2eB6BMu>. Acesso em: 8 nov. 2016. p. 591-593.

94 Ver nota 32.
} 
É mais fácil aprimorar os sistemas de adjudicação através de mudanças paulatinas do que transplantando práticas e instituições de outros países. 950 transplante de instituições e práticas de direito administrativo de um país para outro é difícil. Cada país levou décadas para construir seu direito administrativo, talvez séculos, através de compromissos legais e políticos. Culturas legais e estruturas constitucionais (como, por exemplo, disposições sobre separação de poderes) variam drasticamente e restringem as possibilidades de mudança. Ao contrário de áreas como o direito comercial, não há uma razão que obrigue um país a adequar seu direito administrativo ao dos países vizinhos ou de seus parceiros comerciais. As elites de cada país, como os advogados, tendem a temer mudanças e resistem à destruição do seu capital humano (isto é, o conhecimento sobre a forma como o sistema existente pode ser utilizado para funcionar para seus clientes). Oficiais do governo compreensivelmente temem mudanças institucionais que podem ameaçar seu poder ou trazer confusão, resistência política ou litígios constitucionais dispendiosos. Certamente, a regra "se não está quebrado, não conserte isso" está em jogo. Uma mudança significativa, mesmo em uma prática administrativa inadequada, poderia introduzir problemas ainda maiores.

Essa resistência a mudanças em práticas governamentais enraizadas é uma espécie de "dependência da trajetória". Dependência da trajetória significa que a forma como as coisas vêm sendo feitas habitualmente é a forma como elas provavelmente continuarão sendo feitas, ainda que a prática existente seja um não otimizado equilíbrio entre precisão, eficiência e justiça. 96 Uma ilustração frequente da dependência da trajetória é o "qwerty" layout de um teclado em inglês. ${ }^{97}$ Qwerty talvez não seja o melhor arranjo, mas é o mais conhecido e os custos da adoção de um novo layout provavelmente superariam os benefícios da mudança. Assim, países que utilizam métodos inquisitórios de justiça no direito penal tendem a resistir à importação de modelos adversariais na adjudicação administrativa. Aqueles acostumados à adjudicação dentro de agências com funções de investigação ou de persecução tendem a resistir à supressão das funções de adjudicação dessas agências. Aqueles acostumados à revisão judicial

95 O objeto do transplante em direito comparado é algo controvertido. Eu não posso ingressar nesses debates aqui. Regras e instituições copiadas de outros países são sempre transformadas no país de destino, tendo em vista a tendência de que ambos os países possuam tradição jurídica e cultural distintas. Ver, e.g., GOLDBACH, Toby S.; BRAKE, Benjamin ; KATZENSTEIN, Peter. The Movement of U.S. Criminal and Administrative Law: Processes of Transplanting and Translating. Indiana Journal of Global Legal Studies, Bloomington, v. 20, n. 1, p. 141184, 2013. p. 141.. Eu apenas afirmo aqui que há exemplos de transplantes de procedimentos administrativos aparentemente bem sucedidos e que os legisladores deveriam prestar atenção na forma como outros países lidaram com os problemas para os quais eles estão buscando a solução. Ver o texto das notas 95-102.

96 Ver, e.g., GINSBURG, Tom; MASUR, Jonathan S.; McADAMS, Richard H. Libertarian Paternalism, Path Dependence, and Temporary Law. The University of Chicago Law Review, Chicago, v. 81, p. 291-359, 2014.

97 Ver HATHAWAY, O. A. Path Dependence and the Law: The Course and Pattern of Legal Change in a Common Law System. lowa Law Review, lowa, v. 86, p. 601-611, 2001. 
perante cortes de competência comum irão questionar a criação de cortes administrativas especializadas.

Todavia, tem havido vários casos de transplantes bem sucedidos na história do direito administrativo. Somente para mencionar alguns, a UE adotou importantes elementos do sistema adversarial de julgamento administrativo e de justiça natural após a adesão do Reino Unido.98 Vários países tomaram por empréstimo os modelos de cortes administrativas da França e da Alemanha. Alguns países editaram leis de procedimento administrativo largamente aplicáveis com base no APA dos EUA. Decisões chinesas para adoção de um direito processual foram fortemente influenciadas pelas práticas ocidentais. A legislação estadunidense sobre acesso à informação se espalhou ao redor do mundo, assim como o modelo escandinavo do ombudsman. O Reino Unido adaptou a ideia de um administrative tribunal centralizado da Austrália. Organizações transnacionais pegaram emprestado princípios de direito administrativo dos Estados Unidos e de outros países. 99 Por sua vez, parâmetros de processos justos em organizações como a Organização Mundial do Comércio - OMC passaram a ser aplicados em disputas internas. 100

Portanto, transplantes são possíveis. Um país deveria considerar a introdução de tribunals para a reconsideração de decisões iniciais caso ele sentisse que o seu sistema de revisão judicial está sendo mal avaliado pela população, como aparentemente é o caso do Japão, ou muito lento e dispendioso para decidir questões relativamente simples. Ele poderia fazer uma experiência com cortes especializadas na matéria administrativa, para a revisão de alguns tipos particulares de casos que sobrecarregam o sistema de competência comum. Ele poderia tentar modelos adversariais com o intuito de fortalecer o estágio da decisão inicial ou modelos inquisitórios para fazer com que a decisão inicial seja menos dispendiosa e formal. Um emprego meticuloso de transplantes pode permitir a um país otimizar seu próprio sistema de direito público sem uma ruptura muito brusca com as normas de direito processual que lhe são familiares.

Como exemplo de potencial transplante, propus que os Estados Unidos considerassem fazer uma experiência com um tribunal para a seguridade social. ${ }^{101} \mathrm{O}$ sucesso

\footnotetext{
98 Ver o texto das notas 30-33.

99 GOLDBACH, Toby S.; BRAKE, Benjamin ; KATZENSTEIN, Peter. The Movement of U.S. Criminal and Administrative Law: Processes of Transplanting and Translating. Indiana Journal of Global Legal Studies, Bloomington, v. 20, n. 1, p. 141-184, 2013. p. 168-177.

100 Ver BARAK-EZER, Daphne ; PEREZ, Oren. Whose Administrative Law Is It Anyway? How Global Norms Reshape the Administrative State. Cornell International Law Journal, Nova York, v. 46, n. 3, p. 455-497, 2013. p. 468-72.

101 Ver ASIMOW, Michael; LUBBERS, Jeffrey S. The Merits of "Merits" Review: A Comparative Look at the Australian Administrative Appeals Tribunal. Windsor Yearbook of Access to Justice, Ontário, v. 28, p. 261-284, 2010. p. 281-284; ASIMOW, Michael; WOLFE, Jeffrey S. Thinking Outside the APA Box: A New Social Security Tribunal, Administrative \& Regulatory Law News, Washington, v. 38. n. 2, p. 3-4, 2013. Disponível em: < http://bit.ly/2ffgxPL >. Acesso em: 9 nov. 2016. Um tribunal para a seguridade social poderia ser um primeiro passo na direção
} 
da experiência com tribunals para a seguridade social no Reino Unido e Austrália sugere que essa é uma ideia que poderia funcionar nos Estados Unidos. Existem óbvias questões de escala, tendo em vista que o sistema de seguridade social dos EUA lida com aproximadamente 700.000 pedidos de benefício por incapacidade ao ano.102 No entanto, o British Social Security and Child Support Tribunal lida com aproximadamente 400.000 processos ao ano e os decide em um prazo médio de 22 semanas. 103 Tribunals não são desconhecidos nos Estados Unidos. Por exemplo, o Tax Court funciona bem como um tribunal de tributos federais e os estados rotineiramente utilizam tribunals para a tomada de decisões em processos envolvendo benefícios, como, por exemplo, seguro desemprego e indenização por acidente do trabalho.

O sistema utilizado nos Estados Unidos para decisão sobre benefícios da seguridade social por incapacidade é altamente deficiente. Atualmente, as decisões iniciais nos requerimentos de benefícios por incapacidade no âmbito da seguridade social são proferidas por ALJs contratados pela Social Security Administration (SSA). A reconsideração das decisões dos ALJs é proferida pelo Conselho de Apelação (Appeals Council) da SSA. A revisão judicial tramita na Corte Federal Distrital (Federal District Court) (e há um grande volume desses casos). A Seguridade Social é atormentada por um acúmulo quase desanimador de processos ainda não decididos, um problema que deve apenas se agravar conforme as mudanças demográficas forem aumentando o número de requerentes de benefícios por incapacidade. Normalmente leva mais do que dois anos para que esses requerentes doentes e desempregados consigam um julgamento. Além disso, existe uma profunda desconfiança entre os ALJs e a SSA sobre várias medidas que a SSA adotou para aumentar a produtividade e avaliar a qualidade do trabalho dos ALJs. Outro problema é que não há número suficiente de ALJs para reduzir o acervo, mas o sistema de contratação de mais ALJs pelo Office of Personnel Management está embaraçoso e insatisfatório em variados aspectos (até porque ele dá preferência a veteranos militares o que importa em discriminação contra as mulheres). A revisão judicial

\footnotetext{
de um tribunal para benefícios federais. Esse tribunal para benefícios poderia adjudicar processos envolvendo a seguridade social, juntamente com os processos envolvendo benefícios dos veteranos de guerra, que são atualmente decididos pela Veterans Administration e os casos de doenças pulmonares geradas pela inalação do pó de carvão, que são atualmente resolvidos pelo Labor Department.

102 Informações sobre U.S. SOCIAL SECURITY ADMINISTRATION. Social Security's Hearings and Appeals Process .Disponível em: < http://www.socialsecurity.gov/appeals/>. Acesso em: 11 nov. 2016.

103 REINO UNIDO. Ministry of Justice, HM Courts; Tribunals Service. Social Security and Child Support Statistics: 1 April 2010 to 31 March 2011, at 4 (n.d.). Disponível em:< http://bit.ly/2g7nfFh >. Acesso em: 11 nov. 2016. O tribunal da seguridade social utiliza majoritariamente métodos inquisitórios ao invés de adversariais. THOMAS, R. From "Adversarial v. Inquisitorial" to "Active, Enabling, and Investigative": Developments in UK Administrative Tribunals. In: JACOBS, L.; BEGLAY, S. (Ed.). The Nature of Inquisitorial Processes in Administrative Regimes. Londres: Routledge, 2013. p. 51-70. Thomas declara que o tribunal da seguridade social decide 450.000 processos por ano, em um tempo médio de vinte e cinco semanas por processo. THOMAS, Robert. Administrative Justice, Better Decisions, and Organizational Learning. Public Law, Londres, p. 111-131, 2015. p. 6. (manuscrito).
} 
de milhares de processos da seguridade social na Corte Federal Distrital sobrecarrega os juízes e pode representar uma subutilização dos recursos judiciários.

Um tribunal para a seguridade social poderia retirar os administrative judges da SSA. Os atuais ALJs poderiam ser transferidos para o novo tribunal e poderiam continuar sendo protegidos contra a demissão injustificada. Todavia, os ALJs não poderiam mais usufruir das disposições elaboradas para assegurar-lhes a independência decisória atualmente proporcionada pelo APA. ${ }^{104}$ Consequentemente, o tribunal poderia ser livre para contratar seus próprios juízes, admitindo os candidatos mais qualificados sem as restrições do sistema atual e sem a preferência pelos veteranos. Ele poderia instituir um sistema probatório de modo que os novos juízes que ficassem abaixo da expectativa pudessem ser facilmente eliminados. O tribunal poderia ser autorizado a valer-se de variadas ferramentas gerenciais que atualmente não são utilizadas, como a avaliação dos juízes e revisão pelos pares. O tribunal poderia empregar juízes temporários, aposentados, por meio período ou mesmo leigos, até que o acúmulo de processos fosse reduzido. $O$ ingresso de novos juízes permitiria que o novo tribunal realizasse audiências mais rapidamente do que é possível com o limitado quadro atual de juízes da seguridade social e isso permitiria a eles proceder a um julgamento colegiado ao invés de monocrático. Outra reforma que poderia ser introduzida simultaneamente é a criação de um tribunal de apelação para a seguridade social (como o United Kingdom's Upper Tribunal). Se existisse um tribunal de apelação, o Congresso poderia contribuir para a redução do volume de processos envolvendo a seguridade social que atualmente sobrecarrega as Cortes Federais Distritais. Ele poderia, por exemplo, limitar a jurisdição das cortes às questões de direito, excluindo as questões de fato. Subsidiariamente, poderia existir uma corte especializada em benefícios para a revisão de decisões envolvendo a seguridade social (semelhante à Veterans Court). Todas essas ideias são essencialmente transplantes de outros sistemas que aparentam estar funcionando bem, ainda que elas não se afastem drasticamente da cultura jurídica dos EUA, uma vez que há estruturas similares funcionando nos EUA.

\section{CONCLUSÃO}

Todo país deve elaborar um sistema para solução do grande número de conflitos entre particulares e agências governamentais. Esse sistema de vital importância é a

\footnotetext{
104 O sistema de ALJ foi criado com a finalidade de assegurar a independência para os adjudicadores (então conhecidos como hearing officers) integrantes das agências com funções combinadas. Ver nota 19 (relacionando as garantias que asseguram a independência do ALJ); ASIMOW, Michael. The Administrative Judiciary: ALJ's in Historical Perspective. Journal of the National Association of Administrative Law Judiciary, California, v. 20, n. 1, p. 157-165, 2000; VERKUIL, Paul; GIFFORD, Daniel; KOCH Jr., Charles; PIERCE Jr., Richard; LUBBERS, Jeffrey. The Federal Administrative Judiciary. Administrative Conference of the U.S.: Recommendations and Reports. v. 2. Washington, 1992. Esse elevado nível de proteção da independência dos julgadores não seria necessário se eles trabalhassem em um tribunal independente ao invés de uma agência com funções combinadas.
} 
face da justiça para milhões de pessoas comuns. Ele deveria ser delineado de maneira a maximizar sua utilidade através da otimização do equilíbrio entre precisão, eficiência e justiça.

Esse artigo descreveu cinco modelos de sistemas de adjudicação administrativa empregados por uma grande variedade de países. Esses modelos diferem entre si na escolha se a decisão inicial, a reconsideração ou a revisão judicial será o principal ponto de controle de eventuais erros governamentais. Eles também se distinguem na forma como cada país associa um conjunto limitado de variáveis: agências com funções combinadas versus tribunal separado; processo adversarial versus inquisitório; revisão judicial aberta versus revisão judicial fechada; cortes especializadas versus cortes de competência comum. Essas escolhas estabelecem uma forte dependência da trajetória e refletem a cultura jurídica de cada país, bem como um compromisso político.

Esse texto não expressa uma preferência normativa dentre os cinco modelos. Não há um único modelo claramente superior para o exercício da adjudicação administrativa; melhor dizendo, cada sistema poderia ser aperfeiçoado através de uma cuidadosa remodelação e de um aproveitamento estratégico de procedimentos utilizados em outros países, assim como mediante proteções adicionais para a independência decisória e um adequado nível do quadro de pessoal e de recursos para a execução dessa tarefa.

\section{REFERÊNCIAS}

ALLARS, Margaret. The Nature of Merits Review: A bold vision realised in the administrative appeals tribunal. Federal Law Review, Canberra, v. 41, n. 2, p. 197-226, 2013.

ASIMOW, Michael; DUNLOP, Lisl. The Many Faces of Administrative Adjudication in the European Union. Administrative Law Review, Washington, v. 61, p. 131-170, 2009.

ASIMOW, Michael; LUBBERS, Jeffrey S. The Merits of "Merits" Review: A Comparative Look at the Australian Administrative Appeals Tribunal. Windsor Yearbook of Access to Justice, Ontário, v. 28, p. 261-284, 2010. Disponível em: < http://bit.ly/2fC1SeE >. Acesso em: 8 nov. 2016.

ASIMOW, Michael; WOLFE, Jeffrey S. Thinking Outside the APA Box: A New Social Security Tribunal, Administrative \& Regulatory Law News, Washington, v. 38. n. 2, p. 3-4, 2013. Disponível em: < http://bit.ly/2ffgxPL>. Acesso em: 9 nov. 2016.

ASIMOW, Michael. The Administrative Judiciary: ALJ's in Historical Perspective. Journal of the National Association of Administrative Law Judiciary, California, v. 20, n. 1, p. 157-165, 2000.

ASIMOW, Michael. The Spreading Umbrella: Extending the APA's Adjudication Provisions to All Evidentiary Hearings Required by Statute. Administrative Law Review, Washington, v. 56, p. 1003-1008, 2004. 
AUBY, Jean-Bernard; CLUZEL-M’ETAYER, Lucie. Administrative Law in France. In: SEERDEN, Réne (Ed.). Administrative Law of The European Union, Its Member States and The United States. 2. ed. Cambridge: Intersentia, 2007. p. 61-92.

BALBIN, Carlos F. Manual de Derecho Administrativo. Buenos Aires: La Ley, 2011.

BARAK-EZER, Daphne; PEREZ, Oren. Whose Administrative Law Is It Anyway? How Global Norms Reshape the Administrative State. Cornell International Law Journal, Nova York, v. 46, n. 3, p. 455-497, 2013. Disponível em: <http://bit.ly/2fmkv73>. Acesso em: 9 nov. 2016.

BIGNAMI, Francesca. Creating European Rights: National Values and Supranational Interests. Columbia Journal of European Law, Nova York, v. 11, p. 241-352, 2005. Disponível em: < http://bit. ly/2fBy95h>. Acesso em 8 nov. 2016.

BIGNAMI, Francesca. From Expert Administration to Accountability Network: A New Paradigm for Comparative Administrative Law. American Journal of Comparative Law, Washington, v. 59, n. 4, p. 859-908, 2011. Disponível em : < http://bit.ly/2fB7khl>. Acesso em: 8 nov. 2016.

BROWN, L. Neville; BELL, John S. French Administrative Law. Toronto: Oxford University Press, 5. ed., 1998.

CRAIG, Paul. EU Administrative Law. 2. ed. Nova York: Oxford University Press, 2012.

CRAIG, Paul. Judicial Review, Appeal and Factual Error. Public Law, Londres, p. 788-807, 2004.

CRAIG, Paul. Perspectives on Process: Common Law, Statutory and Political. Public Law, Londres, n. 2, p. 275-296, 2010. Disponível em: <http://bit.ly/2fBEduX>. Acesso em 8 nov 2016.

CRAMTON, Roger. A Comment on Trial-Type Hearings in Nuclear Power Plant Siting. Virginia Law Review, Charlottesville, v. 58, n. 4, p. 585-599, 1972. Disponível em: < http://bit.ly/2eB6BMu>. Acesso em: 8 nov. 2016.

ELLIOTT, Mark; THOMAS, Robert. Tribunal Justice, Cart, and Proportionate Dispute Resolution. Cambridge Law Journal, Cambridge, v. 71, n. 2, p. 297-324, 2012.

ELLIOTT, Mark. Ombudsmen, Tribunals, Inquiries: Re-Fashioning Accountability Beyond the Courts. Legal Studies Research Papers Series, Cambridge, n. 21, 2012. Disponível em: <http:// bit.ly/2fkVPMc>. Acesso em: 8 nov. 2016.

EUROPEAN COMMISSION. Antitrust: Manual of Procedures. Bruxelas: European Comission Office, 2012. Disponível em: <http://bit.ly/2fAzc7p>. Acesso em: 8 nov. 2016.

GAROUPA, Nuno; OGUS, A.; SANDERS, Andrew. The Investigation and Prosecution of Regulatory Offenses: Is there an Economic Case for Integration. Cambridge Law Journal, Cambridge, v. 70, n. 1, p. 229-259, 2011. Disponível em: <http://bit.ly/2fkYqG0>. Acesso em: 8 nov. 2016.

GIFFORD, Daniel J. Federal Administrative Law Judges: The Relevance of Past Choices to Future Directions. Administrative Law Review, Washington, v. 49, n. 1, p. 4-5, 1997. 
GINSBURG, Tom; HOETKER, Glenn. The Unreluctant Litigant? An Empirical Analysis of Japan's Turn to Litigation. Journal of Legal Studies, Chicago, v. 35, n. 1, p. 31-59, 2006.

GINSBURG, Tom; MASUR, Jonathan S.; McADAMS, Richard H. Libertarian Paternalism, Path Dependence, and Temporary Law. The University of Chicago Law Review, Chicago, v. 81, p. 291-359, 2014. Disponível em: < http://bit.ly/2eDpcrp>. Acesso em: 9 nov. 2016.

GINSBURG, Tom. Confucian Constitucionalism? Globalization and Judicial Review in Korea and Taiwan. Law and Social Inquiry, [S.I.], v. 27, n. 4, p. 763-799, 2002.

GINSBURG, Tom. Dismantling the "Developmental State?" Administrative Procedure Reform in Japan and Korea. The American Journal of Comparative Law, Chicago, v. 49, n. 4, p. 585-625, 2001.

GOLDBACH, Toby S.; BRAKE, Benjamin; KATZENSTEIN, Peter. The Movement of U.S. Criminal and Administrative Law: Processes of Transplanting and Translating. Indiana Journal of Global Legal Studies, Bloomington, v. 20, n. 1, p. 141-184, 2013.

HATHAWAY, Oona A. Path Dependence and the Law: The Course and Pattern of Legal Change in a Common Law System. lowa Law Review, lowa, v. 86, p. 601-611, 2001. Disponível em: < http:// bit.ly/2fCQpgl>. Acesso em: 9 nov. 2016.

HE HAIBO. Litigation Without a Ruling: The Predicament of Administrative Law in China, Tsinghua China Law Review, Pequim, v. 3, p. 257-280, 2011. Disponível em: <http://bit.ly/2fBasKB > Acesso em: 8 nov. 2016.

HERBERT, Georg. Administrative Justice in Europe - Report for Germany [S.I.: n.d.]. Disponível em: < http://bit.ly/2gliROb >. Acesso em: 9 nov. 2016.

JORDÃO, Eduardo; ROSE-ACKERMAN, Susan. Judicial Review of Executive Policymaking in Advanced Democracies Beyond Rights Review. Administrative Law Review, Washington, v. 66, n. 1, p. $1-72,2014$.

KINKEL, Jonathan; HURST, William. Review Essay — Access to Justice in Post-Mao China: Assessing the Politics of Criminal and Administrative Law. Journal of East Asian Studies, Cambridge, v. 11, n. 3, p. 467-499, 2011.

MAHBOUBI, Neysun. Suing the Government in China. In: ZHOU, K.; RIGGER, S.; WHITE III, L. (Ed.). Democratization in China, Korea, and Southeast Asia. Londres: Routledge, 2014. p. 141-155.

MASSOT, Jean. The Powers and Duties of the French Administrative Law Judge. In: ROSE-ACKERMAN, Susan ; LINDSETH, Peter (Eds.). Comparative Administrative Law. Cheltenham: Edward Elgar Publishing, 2010. p. 415-425.

MINZNER, Carl F. China's Turn Against Law. American Journal of Comparative Law, [S.I.], vol. 59, p. 935-984, 2011. Disponível em: < http://bit.ly/2fAsG0s> . Acesso em: 8 nov. 2016. 
MINZNER, Carl F. Xinfang: Alternative to Formal Chinese Legal Institutions. Stanford Journal International Legal, Stanford, v. 42, p. 103-179, 2006.

NEMPO, Shiho Tokei. [Relatório Anual de Estatísticas Judiciais], tbl.4, [S.I.] 2012. Disponível em Japonês em: <http://www.courts.go.jp/sihotokei/nenpo/pdf/B24DMIN4.pdf>. Acesso em: 11 nov. 2016.

PALMER, Michael. Compromising Courts and Harmonizing Ideologies: Mediation in the Administrative Chambers of the People's Republic of China In: HARDING, A.; NICHOLSON, P. (Ed.). New Courts in Asia. Londres \& Nova York: Routledge, 2010.

PEERENBOOM, Randall. Judicial Independence in China: Common Myths and Unfounded Assumptions. La Trobe Law School Legal Studies Research Paper, Melbourne, no 11, sept. 2008. Disponível em: < http://bit.ly/2fLYxZW>. Acesso em: 11 nov. 2016.

PEERENBOOM, Randall. Judicial Independence in China: Lessons for Global Rule of Law Promotion. Nova York: Cambrigde University Press, 2010.

RABIN, Robert. Federal Regulation in Historical Perspective. Standford Law Review, Stanford, v. 38, n. 5, p. 1189-1326, 1986.

RAMSEYER, Mark; NAKAZATO, Minoru. Japanese Law: An Economic Approach. Chicago: The University of Chicago Press, 1999.

SCHRÖDER, Meinhard. Administrative Law in Germany. In: SEERDEN, Réne (Ed.). Administrative Law of The European Union, Its Member States, and The United States. 2. ed. Cambridge: Intersentia, 2007. p. 91-154.

SCHWARTZ, Bernard. French Administrative Law And The Common Law World. New York: New York University Press, 1954.

SINGH, Mahendra P. German Administrative Law in Common Law Perspective. 2. ed., v. 149. Berlin: Springer, 2001.

THOMAS, Robert. Administrative Justice, Better Decisions, and Organizational Learning. Public Law, Londres, p. 111-131, 2015.

THOMAS, Robert. From "Adversarial v. Inquisitorial" to "Active, Enabling, and Investigative": Developments in UK Administrative Tribunals. In: JACOBS, Laverne; BEGLAY, Sasha (Ed.). The Nature of Inquisitorial Processes in Administrative Regimes. Londres: Routledge, 2013. p. 51-70. Disponível em: <http://bit.ly/2fBVHaj>. Acesso em: 8 nov. 2016.

USHIJIMA, Hitoshi. Administrative Law and Judicialized Governance in Japan. In: GINSBURG, Tom; CHEN, Albert H.Y. (Eds.). Administrative Law And Governance In East Asia. Londres : Routledge, 2009. p. 81-100. 
VERKUIL, Paul; GIFFORD, Daniel; KOCH Jr., Charles; PIERCE Jr., Richard; LUBBERS, Jeffrey. The Federal Administrative Judiciary. Administrative Conference of the U.S.: Recommendations and Reports. v. 2. Washington, 1992.

WADE, H.W. R.; FORSYTH, C. F. Administrative Law. 10th ed. Oxford: Oxford University Press, 2009. WEI CUI. Foreign Administrative Law and International Taxation: A Case Study of Treaty Implementation in China. Administrative Law Review, Washington, v. 64, p. 191-233, 2012.

WILS, Wouter P. J. The Role of the Hearing Officer in Competition Proceedings Before the European Commission. World Competition: Law and Economics Review, [S.I.], v. 35, n. 3, p. 431-456, 2012. Disponível em: <http://bit.ly/2fY9c8F> . Acesso em: 8 nov. 2016. 